\title{
Thermal Stability, Grain Growth Kinetics, and Mechanical Properties of Bulk Ultrafine-Grained AA6063/SiC Composites with Varying Reinforcement Sizes
}

\author{
O.B. BEMBALGE and S.K. PANIGRAHI
}

\begin{abstract}
Bulk ultrafine-grained (UFG) AA6063/4wt pct SiC composites with varying reinforcement sizes [12 $\mu \mathrm{m}$ (coarse), $1 \mu \mathrm{m}$ (fine), and $45 \mathrm{~nm}$ (nano)] have been developed by a hybrid route of stir-casting and cryorolling. In the current study, the influence of annealing temperatures $(423 \mathrm{~K}$ to $573 \mathrm{~K}$ ) on the precipitation evolution, particle-stimulated nucleation (PSN), recrystallization, grain growth kinetics, and thermal stability of developed bulk UFG composites have been studied, and the resultant effect of microstructural evolution is correlated with mechanical properties. UFG coarse and UFG fine composites have shown evidence of recrystallized grains via PSN and retained their UFG microstructure up to $473 \mathrm{~K}$ and $523 \mathrm{~K}$, respectively. Superior microstructural stability with retained UFG microstructure up to $573 \mathrm{~K}$ was observed in the UFG nanocomposite due to the effective pinning of nano-SiC particles and precipitates along grain boundaries. This ultimately resulted in the increased grain growth activation energy and strength of the UFG nanocomposite. However, the overall increase in strength is maximum in the UFG nanocomposite due to the dominant effect of dislocation strengthening, grain boundary strengthening, and precipitation strengthening mechanisms. A thorough examination of the microstructural evolution of UFG composites at different annealing temperatures along with their mechanical behavior is presented in this paper.
\end{abstract}

https://doi.org/10.1007/s11661-019-05342-6

(C) The Minerals, Metals \& Materials Society and ASM International 2019

\section{INTRODUCTION}

THE development of bulk ultrafine-grained (UFG)/nanostructured (NS) metal matrix composites (MMC) is of peak interest due to their enhanced mechanical properties compared with coarse-grained counterparts. ${ }^{[1]}$ Among UFG MMCs, UFG particulate aluminum metal matrix composites (AMMC) have drawn considerable attention in academic research and industrial applications. ${ }^{[2,3]}$ Severe plastic deformation (SPD) methods are being extensively used to develop bulk UFG composites. Accumulative roll bonding $(\mathrm{ARB}),{ }^{[4,5]}$ equal channel angular pressing (ECAP) ${ }^{[6]}$ high-pressure torsion (HPT), ${ }^{[\top]}$ and friction stir processing $(\mathrm{FSP})^{[8,9]}$ are well-established SPD techniques used to develop bulk UFG composites. These deformation techniques store a high fraction of dislocation density in

O.B. BEMBALGE and S.K. PANIGRAHI are with the Department of Mechanical Engineering, Indian Institute of Technology Madras, Chennai, 600036, India. Contact e-mail: skpanigrahi@iitm.ac.in

Manuscript submitted August 25, 2018.

Article published online July 2, 2019 the matrix, refine the microstructure in the UFG/NS regime and hence impart extraordinary properties to UFG composites. SPD-processed materials often possess high stored energy. However, this stored energy in UFG/NS composites may lead to high thermal instability and make the microstructure unstable. ${ }^{[10-13]}$ When such composites with UFG/NS grains are subjected to thermal cycles, they have the tendency to minimize the energy for grain growth by decreasing the grain boundary area and result in the loss of UFG/NS structure. ${ }^{[14]}$ Furthermore, in addition to the UFG/NS grain structure, the SPD-processed composite materials also possess fine dislocation structures with a large number of stored dislocations. ${ }^{[15]}$ The density of dislocation changes with a reduction in reinforcement particle size. ${ }^{[16]}$ The dislocation structures are even highly thermally unstable compared to the grain structures developed by various SPD techniques. ${ }^{[4-18]}$ Therefore, the thermal stability of UFG composite materials developed by any SPD process should be thoroughly examined before considering them for any engineering application.

The thermal instability of UFG/NS composite materials processed through different SPD techniques is a considerable issue, and only limited studies have been 
reported addressing this problem. ${ }^{[19-23]}$ The thermal stability of the UFG composite varies with varying SPD processing routes and reinforcement sizes. ${ }^{[24-27]}$ Jafarian et al. ${ }^{[28]}$ stated that the $\mathrm{Al} / \mathrm{TiC}$ (nano-TiC) composite developed by the ARB process was thermally stable below $523 \mathrm{~K}$ for 30 minutes of the heating cycle, with an average grain size of $600 \mathrm{~nm}$. Lipecka et al. ${ }^{[21]}$ reported that the $\mathrm{Al} / \mathrm{CNT}$ composite developed by the powder metallurgy and hot extrusion method was thermally stable up to $823 \mathrm{~K}$ for 10 minutes, with an average grain size of $500 \mathrm{~nm}$. Hitherto, most of the research explorations have been circumscribed to the thermal stability of UFG composites with nano-reinforcement particles for shorter periods of annealing time. ${ }^{[19-28]}$ In addition, there is a lack of information on the thermal stability of UFG composites within the entire range of reinforcement particle size (from coarse to nano) for a longer duration of time, which may widen the temperature range of their application.

The UFG composites are mostly fabricated either at room temperature or at ambient temperature. ${ }^{[19-28]}$ However, a $373 \mathrm{~K}$ rise in temperature was experienced by Ghazani et al. ${ }^{[29]}$ when the composite was ECAPed at room temperature. The temperature rise was attributed to extensive plastic deformation and frictional heat generated during the SPD process. This increase in temperature gives rise to the recovery of material by dislocation annihilation, which may shorten the thermal response of UFG composites. On the other hand, such a rise in temperature may cause dynamic aging in the case of age-hardenable matrix materials, which in turn reduce the post-age hardenability. To overcome the abovementioned limitations and to increase the thermal response of UFG composites, a low-temperature SPD technique is preferable.

Therefore, in the current investigation, an attempt has been made to study the thermal stability of UFG composites (developed at liquid nitrogen temperature) with varying reinforcement sizes ranging from the nanometer-to-coarse micrometer scales for a longer duration of annealing time (1 hour). A hybrid processing route of stir-casting and cryorolling has been adopted to develop AA6063/SiC UFG composites. The details of manufacturing routes are established in the current authors' recent research communication. ${ }^{[16]}$ As per the authors' knowledge, no publications are available to date on the thermal stability of bulk UFG composites (with varying reinforcement sizes) fabricated by cryorolling-based manufacturing routes. Therefore, the thermal stability study of UFG composites with varying reinforcement size via cryorolling is of prime interest.

The objectives of the current study are (a) to study the synergetic effect of cryorolling and varying reinforcement size (in the nanometer-to-micrometer ranges) on the thermal stability of UFG AA6063/SiC composites at different annealing temperatures with long exposure times (1 hour); (b) to establish the recrystallization mechanism and grain growth kinetics of different UFG AA6063/SiC composites; and (c) to correlate the microstructural evolution during annealing with the mechanical properties of different UFG AA6063/SiC composites.

\section{EXPERIMENTAL METHOD}

In the current study, a commercially available AA6063 alloy was used as a matrix, and three different sizes of $\alpha$-SiC particles (in polycrystalline form) were used as reinforcement. The major alloying elements of the matrix alloy (AA6063) are listed in Table I. The SiC reinforcement particles were obtained from Alfa Aesar with different sizes of $12,1 \mu \mathrm{m}$, and $45 \mathrm{~nm}$, and they are designated as coarse, fine, and nano, respectively.

The AA6063 alloy and 4 wt pct of SiC particles with varying sizes were used to fabricate bulk UFG composites by a hybrid manufacturing route of stir-casting and solution treatment followed by cryorolling. In the first stage, individual plates of coarse, fine, and nano-SiC particles reinforced into the AA6063 matrix were developed via a stir-casting process. A bottom-pouring stir-casting furnace was used to melt the AA6063 alloy at $923 \mathrm{~K}$ temperature. At this temperature, stirring was performed for 5 to 10 minutes to create a semisolid melt alloy vortex. The capsules of SiC powders wrapped in aluminum foil were added into a semisolid melt alloy vortex. The mixture of semisolid alloy and $\mathrm{SiC}$ powder was then stirred by a two-stage stirrer at $500 \mathrm{rpm}$ for 10 minutes. To increase the fluidity of the composite mixture, the temperature was raised to $973 \mathrm{~K}$ and maintained for 10 minutes. The bottom pouring arrangement was used to pour the molten mixture of alloy and $\mathrm{SiC}$ powder into the die of size $300 \times 100 \times 11 \mathrm{~mm}^{3}$. The same method was used to cast all three types of composites, followed by partial rolling to 20 pct to remove the porosity. Later, solution treatment was performed at $803 \mathrm{~K}$ for 2 hours on the partially rolled cast plates, which was followed by cold water quenching. In the second stage, the solution-treated samples were cryorolled up to a thickness reduction of 90 pct. Cryorolling was performed on a rolling mill of $110 \mathrm{~mm}$ diameter at a speed of $8 \mathrm{rpm}$ at liquid nitrogen temperature. To maintain a uniform temperature before and after each rolling pass, samples were immersed for 10 minutes in liquid nitrogen. To avoid ambiguity, the cryorolled base alloy is designated as UFG base alloy (UFGB). Cryorolled UFG composites with coarse, fine, and nano-SiC particles are designated as UFG coarse composite (UFGCC), UFG fine composite (UFGFC), and UFG nanocomposite (UFGNC), respectively, as listed in Table II. The details of the stir-casting and cryorolling processes to fabricate UFG AA6063/4wt pet SiC composites with different reinforcement sizes have been explained in the authors' previous work. ${ }^{[16]}$

All four UFG materials were annealed to understand the effect of reinforcement particle size, precipitation, grain growth, and PSN on thermal stability during annealing. The annealing treatment was carried out at temperatures ranging from $423 \mathrm{~K}$ to $573 \mathrm{~K}$ for a time duration of 1 hour followed by water quenching. Microstructural changes during annealing and their resultant effects on mechanical properties were also studied. Microstructural features were analyzed with the help of electron backscattered diffraction (EBSD) and transmission electron microscopy (TEM). EBSD and 
Table I. Major Alloying Elements of the AA6063 Alloy

\begin{tabular}{lccccccccc}
\hline Elements & $\mathrm{Mg}$ & $\mathrm{Si}$ & $\mathrm{Cr}$ & $\mathrm{Cu}$ & $\mathrm{Fe}$ & $\mathrm{Mn}$ & $\mathrm{Zn}$ & $\mathrm{Ti}$ & $\mathrm{Al}$ \\
\hline Pct Wt & 0.89 & 0.54 & 0.08 & 0.09 & 0.22 & 0.031 & 0.08 & 0.01 & bal. \\
\hline
\end{tabular}

Table II. Designations of UFG AA6063 Alloy and UFG AA6063/SiC Composites

\begin{tabular}{llrr}
\hline Sr. No. & Material Conditions & Avg. SiC Particle Size & Designation \\
\hline 1 & UFG base alloy & - & UFGB \\
2 & UFG coarse composite & $12(\mu \mathrm{m})$ & UFGCC \\
3 & UFG fine composite & $1(\mu \mathrm{m})$ & UFGFC \\
4 & UFG nano composite & $45(\mathrm{~nm})$ & UFGNC \\
\hline
\end{tabular}

TEM samples were prepared by mechanical polishing followed by electropolishing and ion milling, respectively. The electrolyte used in the preparation of EBSD samples comprised methanol and perchloric acid in a volume proportion of $4: 1$ at $15 \mathrm{~V}$ and $243 \mathrm{~K}$.

To study the evolution of phases during annealing and to compute the dislocation density of UFG composites, X-ray diffraction (XRD) analysis was carried out. The Bruker AXS D8 discover diffractometer with a copper source and $K_{\alpha}$ radiation of $\lambda=1.54 \AA$ was used for X-ray diffraction. A similar metallographic procedure followed for EBSD sample preparation was used to prepare the XRD samples. The above-mentioned electrolyte was used to remove any layer of oxide and strain imposed while preparing the samples.

A tensile test was performed on UFGB and UFG composite samples annealed in the temperature range of $423 \mathrm{~K}$ to $573 \mathrm{~K}$. An INSTRON 3365 machine was used to conduct the tensile test at $1 \mathrm{~mm} / \mathrm{min}$ of crosshead velocity. The ASTM E8 standard was followed to prepare tensile samples.

\section{RESULTS}

\section{A. XRD Analysis}

XRD analysis was carried out on the UFGB and UFG composite materials before and after annealing at different temperatures ( $423 \mathrm{~K}$ to $573 \mathrm{~K}$ ) and is shown in Figure 1. The XRD results of the as-cast, solution-treated, and cryorolled composites and their comparative studies were reported in the authors' previous work. ${ }^{[16,30]}$ In the present study, at an annealing temperature of $423 \mathrm{~K}$, no significant changes in XRD maps were observed in the UFGB and UFG composite materials. However, a low-intensity peak of the $\mathrm{Mg}_{2} \mathrm{Si}$ precipitate was observed after an annealing temperature of $473 \mathrm{~K}$ in all UFG materials. The peak intensity of the $\mathrm{Mg}_{2} \mathrm{Si}$ precipitate increased in the annealing temperatures ranging from $523 \mathrm{~K}$ and $573 \mathrm{~K}$, and the peaks of $\mathrm{AlCuMgSi}$ and $\mathrm{AlFeSi}$ precipitates were observed at these temperatures in the UFGB and UFG composite materials (Figures 1(a) through (d)).

Equation [1] ${ }^{[31]}$ was used to calculate the dislocation densities $(\rho)$ of UFGB, UFGCC, UFGFC, and
UFGNC composite materials before and after annealing at various temperatures.

$$
\rho=\frac{2 \sqrt{3} \varepsilon}{D b},
$$

where $\varepsilon$ is the microstrain, $D$ is the crystallite size, and $b$ is the Burgers vector. The values of $\varepsilon$ and $D$ are obtained from XRD peaks via the Williamson-Hall method $^{[32]}$ (Eq. [2]) using X'pert High Score Plus software from PANalytical B.V., Almelo, Netherlands. ${ }^{[33]}$ The XRD peak-broadening effects due to crystallite size $(D)$ and microstrain $(\varepsilon)$ are used in Eq. [2] as follows:

$$
B \cos \theta_{b}=\frac{\lambda K}{D}+\varepsilon \sin \theta_{b},
$$

where $B$ represents the width of the XRD peak (measured at full width at half maximum), $\theta_{\mathrm{b}}$ signifies Bragg's angle, $K$ denotes a material constant (0.9), and $\lambda$ represents the incident radiation wavelength. The instrumental broadening of peak width in UFG materials is compensated by comparing it with the fully annealed AA6063 sample (annealed at $803 \mathrm{~K}$ for 2 hours followed by furnace cooling). This method is used to investigate the crystallite size and microstrain with the help of X'pert HighScore Plus software. These values are further used to calculate the dislocation density using Eq. [1]. A similar procedure was followed by many researchers to calculate the dislocation density using the XRD technique. ${ }^{[10,13,31-33]}$ To minimize the error, three cycles of the XRD test were carried out under each material condition and annealing temperature. The average dislocation density was then calculated to plot the dislocation density $v s$. the annealing temperature graph. The present investigation provides a quantitative analysis of the deviation in dislocation densities among UFGB and UFG composite material conditions.

Figure 2 shows the calculated dislocation densities (from Eq. [1]) of UFGB and UFG composite materials before and after annealing at different temperatures. UFGB and UFG composites exhibited higher dislocation densities before annealing compared to those after annealing. Dislocation density was found to be the highest in UFGNC $\left(4.2 \times 10^{14}\right)$ and decreased with the 


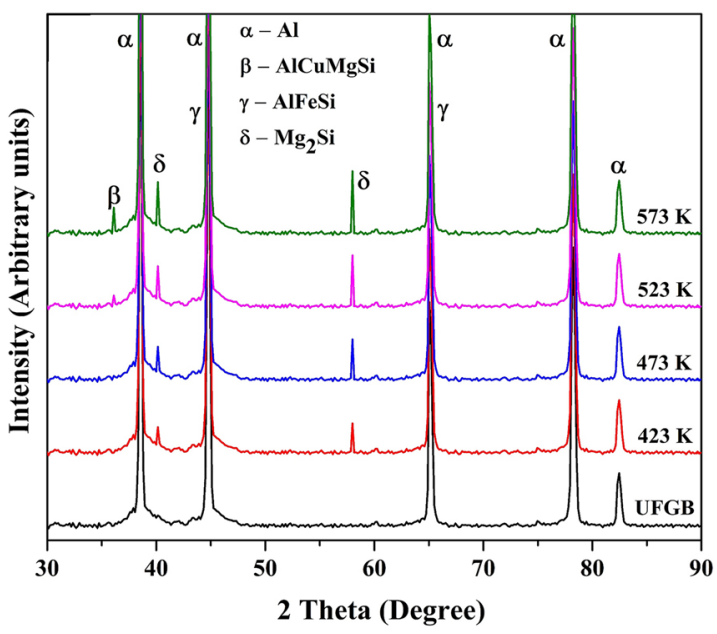

(a)

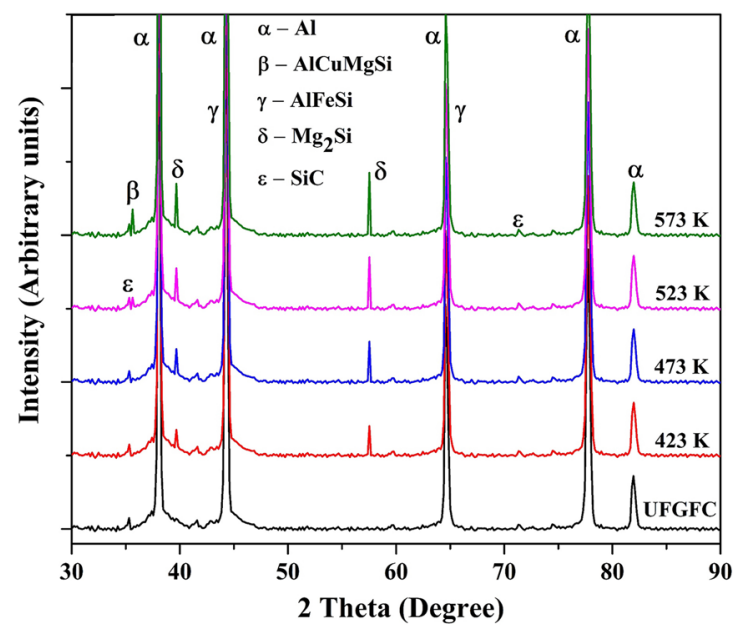

(c)

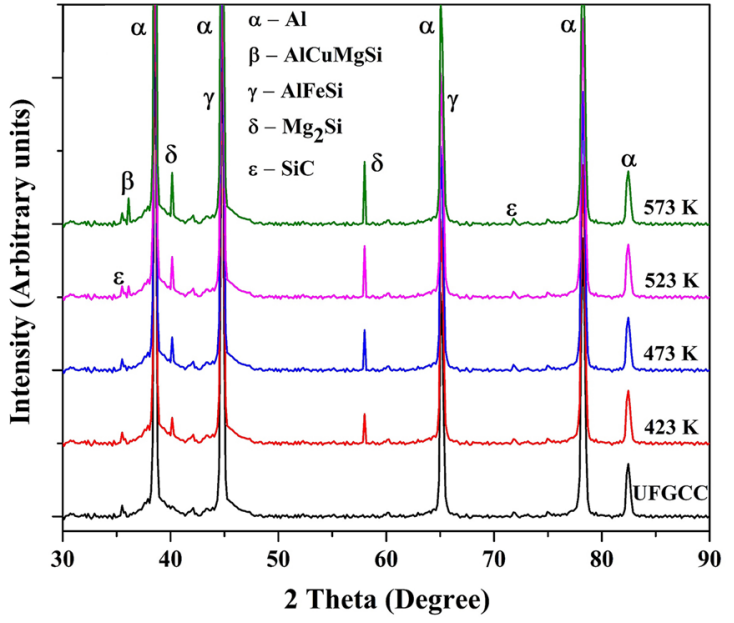

(b)

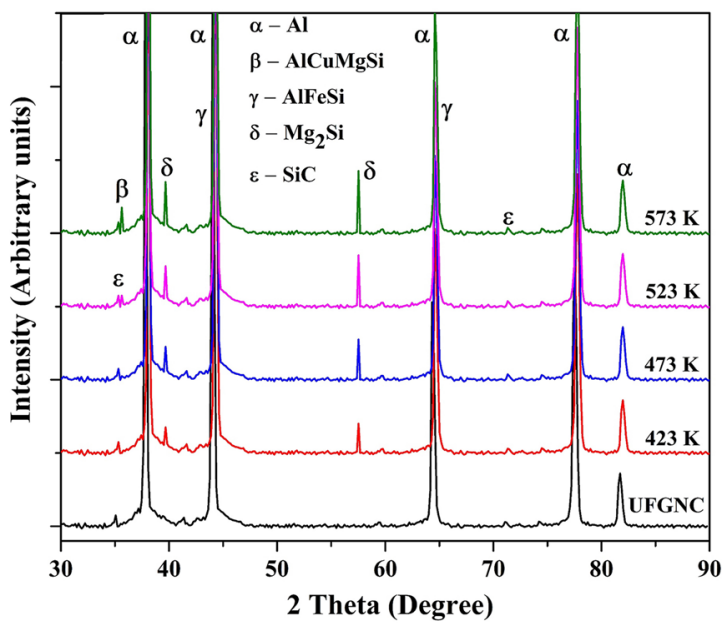

(d)

Fig. 1-XRD profiles of (a) UFGB, (b) UFGCC, (c) UFGFC, and (d) UFGNC subjected to different annealing temperatures for $1 \mathrm{~h}$.

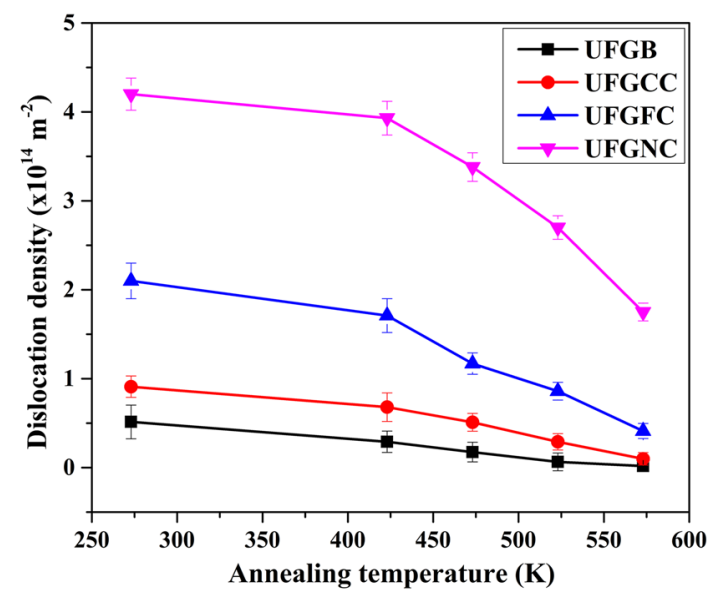

Fig. 2-The dislocation densities of UFGB, UFGCC, UFGFC, and UFGNC at different annealing temperatures.

increasing order of $\mathrm{SiC}$ particle sizes as in the UFGFC $\left(2.1 \times 10^{14}\right)$ and UFGCC $\left(0.91 \times 10^{14}\right)$. The lowest dislocation density was observed in the UFGB $\left(0.514 \times 10^{14}\right)$ compared to the UFG composites before annealing. A drastic reduction in the dislocation densities of the UFGB and UFGCC were observed after annealing at $423 \mathrm{~K}$. A small decrease in the dislocation density of the UFGFC was observed, but there was no significant change in the dislocation density of the UFGNC at $423 \mathrm{~K}$. Further reduction in dislocation density was recorded at $473 \mathrm{~K}$ annealing temperature in the UGB and UFGCC. A substantial decrease in dislocation density was noted in the UFGFC at this temperature. However, a small change in dislocation density was found in the UFGNC. After annealing at $523 \mathrm{~K}$, the UFGB was almost free of dislocations, and the UFGCC showed a small amount of dislocation density due to the mismatch in coefficient of thermal expansion (CTE) of the base alloy and $\mathrm{SiC}$ particles (also termed geometrically necessary dislocations (GNDs)). A rapid reduction in the dislocation density of the UFGFC was observed at $523 \mathrm{~K}$. However, the microstructure of the UFGNC retained a significant fraction of the dislocation density at the same temperature. Moreover, nearly a dislocation-free microstructure was observed at an annealing temperature of $573 \mathrm{~K}$ 
in all UFG materials (UFGB, UFGCC, UFGFC, and UFGNC).

\section{B. Microstructural Evolution of UFG Materials After Annealing}

The microstructural evolution of UFG materials after annealing in the temperature range of $423 \mathrm{~K}$ to $573 \mathrm{~K}$ for 1 hour was analyzed by TEM and EBSD. The deformed and annealed microstructures contained dislocated cell structures, subgrains, ultrafine grains (UFG), and particle-stimulated nucleation (PSN) in regions surrounding the $\mathrm{SiC}$ particles and precipitates, which are represented in the figure by thin yellow arrows, thick yellow arrows, unfilled yellow arrows, yellow dotted circles, and red thin arrows, respectively. Figure 3 shows the deformed microstructure of the UFG base and UFG composite materials before annealing. The UFGB microstructure showed a high density of dislocation along with dislocated cell structures of $150 \pm 50 \mathrm{~nm}$ (Figure 3(a)). The UFGCC consisted of densely packed dislocations in regions surrounding coarse $\mathrm{SiC}$ particles and dislocation cells $(125 \pm 50 \mathrm{~nm})$ in the matrix region away from $\mathrm{SiC}$ particles (Figure 3(b)), which was also reported in the authors' previous work. ${ }^{[16]}$ A polygonized cell structure around the $\mathrm{SiC}$ particles was observed in the UFGFC (Figure 3(c)). The existence of subgrains was also observed in the UFGFC along with the reduced size of dislocated cell structure $(90 \pm 25 \mathrm{~nm})$ compared to the UFGCC. The UFGNC microstructure (Figure 3(d)) appeared to be heavily packed with dislocations. The dislocation cell structures and subgrains in the UFGNC $(80 \pm 20 \mathrm{~nm})$ were found to be in the nanoscale range, smaller than those of the UFGCC and UFGFC materials. Prior to annealing at different temperatures, the presence of secondary compounds (such as $\mathrm{Al}_{4} \mathrm{C}_{3}$ ) located at the interface of the $\mathrm{Al}-\mathrm{SiC}$ was quantified based on TEM and XRD analysis to understand their effect on microstructural evolution. The TEM micrographs of the UFGCC (Figure 3(b)), UFGFC (Figure 3(c)) and UFGNC (Figure 3(d)) showed the interdiffusion of $\mathrm{Al}-\mathrm{SiC}$ without any secondary compound/intermetallic formation (such as $\mathrm{Al}_{4} \mathrm{C}_{3}$ ). These results were also validated with XRD (Figure 1) analysis, which showed no evidence of secondary compound formation such as $\mathrm{Al}_{4} \mathrm{C}_{3}$. These UFG composites were then annealed at various temperatures from $423 \mathrm{~K}$ to $573 \mathrm{~K}$ to understand their microstructural evolution.

Figure 4 presents TEM micrographs of the UFGB and UFG composite materials annealed at $423 \mathrm{~K}$. At this temperature, the initiation of microstructure recovery by the annihilation of dislocations along with a slight reduction in dislocation density was observed in all UFG materials (Figure 4). In the UFGB alloy (Figure 4(a)), fine subgrain structures along with UFG grains of approximately $350 \pm 100 \mathrm{~nm}$ were observed. The UFGCC microstructure contained (Figure 4(b)) (i) partially recrystallized UFG grains along coarse $\mathrm{SiC}$ particles, which were PSN-based (shown by dotted yellow circle), (ii) a fine subgrain structure (thick filled yellow arrow) of $100 \pm 50 \mathrm{~nm}$ and (iii) larger UFG grains $(300 \pm 50 \mathrm{~nm})$ in the matrix region away from coarse $\mathrm{SiC}$ particles, which are marked by thick unfilled arrows. PSN-based recrystallization was also evident in the UFGFC, as shown in Figure 4(c). The size of dislocation cell structures and subgrains was finer in the UFGFC $(250 \pm 50 \mathrm{~nm})$ than in the UFGCC. Finer
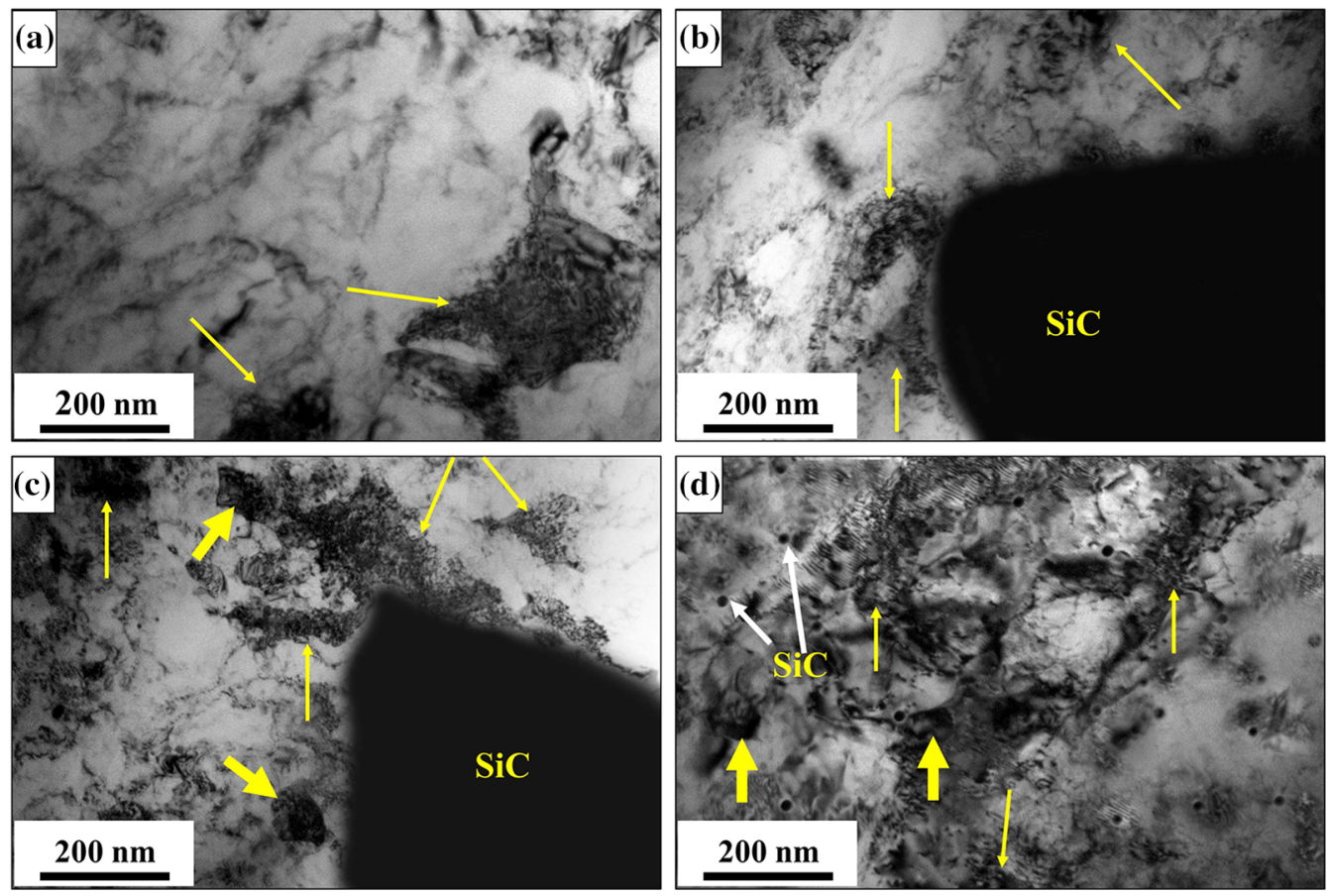

Fig. 3-TEM micrographs of (a) UFGB, (b) UFGCC, (c) UFGFC, and (d) UFGNC under cryorolled conditions. 

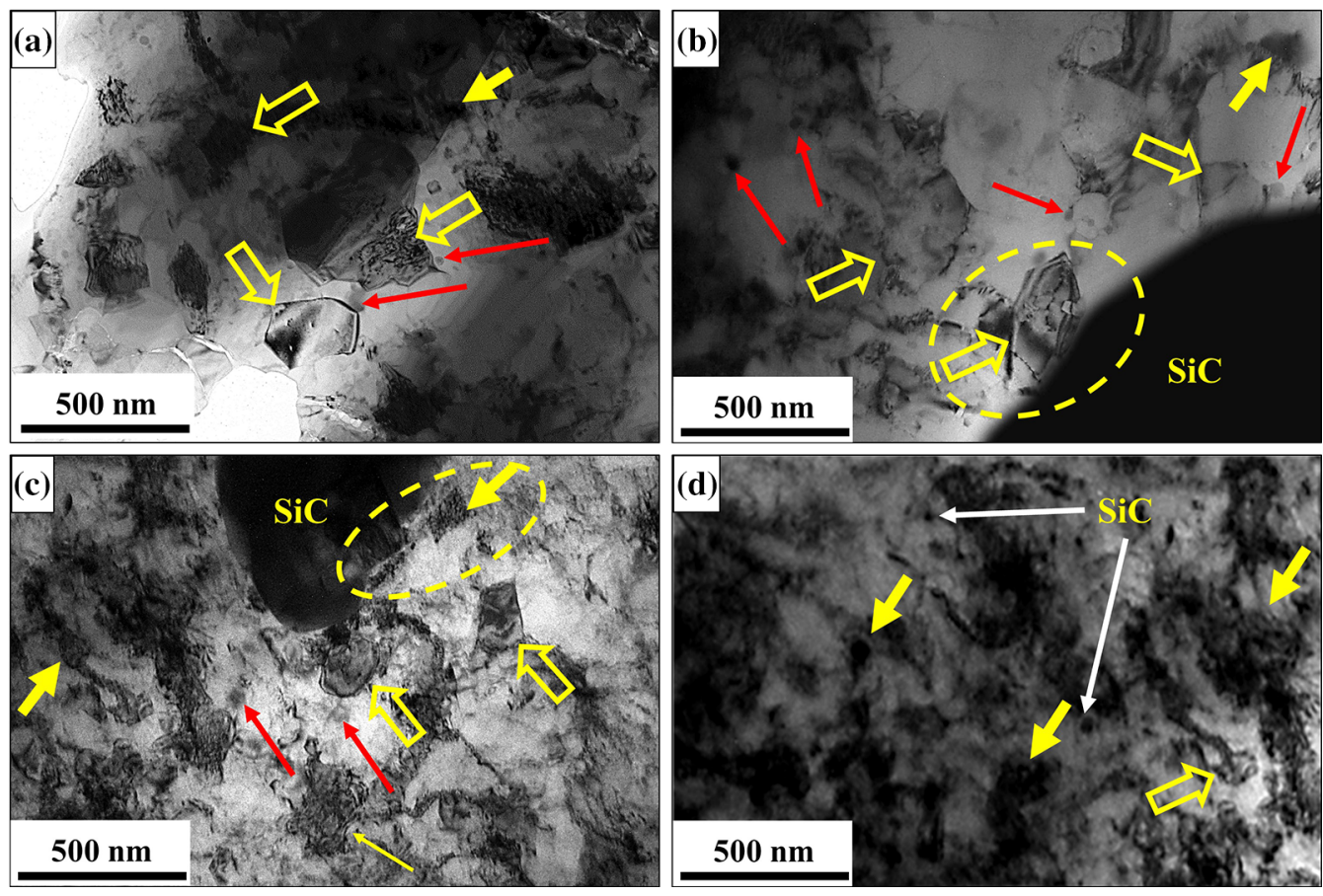

Fig. 4-TEM micrographs of (a) UFGB, (b) UFGCC, (c) UFGFC, and (d) UFGNC annealed at $423 \mathrm{~K}$ (Color figure online).

subgrains of $100 \pm 50 \mathrm{~nm}$ were observed in the UFGNC. There was no significant change in dislocation density in the UFGNC at $423 \mathrm{~K}$ (Figure 4(d)) compared to its nonannealed counterpart (Figure 3(d)). In addition to the recovery and recrystallization phenomena, the nucleation and evolution of spherically shaped GP (Guinier-Preston) zone precipitates also occurred at this annealing temperature $(423 \mathrm{~K})$ in all four materials (Figures 4(a) through (d)). These spherically shaped precipitates were pinned along the grain boundaries, as indicated by the red arrows in Figure 4.

Figure 5 represents the microstructural evolution in UFGB and UFG composite materials subjected to an annealing temperature of $473 \mathrm{~K}$. An accelerated recovery/recrystallization process was observed at this temperature, with further reduction in dislocation density in the UFGB, UFGCC, UFGFC, and UFGNC materials (Figure 5). Recrystallized ultrafine grains of $600 \pm 200$ $\mathrm{nm}$ were observed in the UFGB (Figure 5(a)). Some duplex types of recovery/recrystallization phenomena occurred in the UFGCC material (Figure 5(b)), such as (i) PSN-based recrystallized grains at the SiC-matrix interface and (ii) recrystallized UFG of $500 \pm 100 \mathrm{~nm}$ in the matrix region away from the $\mathrm{SiC}$-matrix interface. In the UFGFC, the polygonized dislocation cells (present along the interface of $\mathrm{SiC}$ particles) transformed into a partially recrystallized UFG structure (Figure 5(c)). A recrystallized UFG microstructure with a grain size of $400 \pm 100 \mathrm{~nm}$ was observed away from fine $\mathrm{SiC}$ particles in the UFGFC. Fine subgrains in the UFGNC were transferred into UFG grains of $200 \pm 100 \mathrm{~nm}$ (Figure 5(d)). In addition to microstructural transformation, at this annealing temperature, the intensity of GP zone precipitates was reduced, and the needle $\left(\beta^{\prime \prime}\right)$ and rod-shaped $\left(\beta^{\prime}\right)$ precipitates evolved in all microstructures of UFG materials (Figure 5). The morphology of the formed precipitates correlated well with the results obtained by other researchers. ${ }^{[34]}$ In addition, the evolution of rod-shaped precipitates $\left(\beta^{\prime}\right)$ along UFG boundaries restricted the grain boundary migration in all UFG materials (Figures 5(a) through (d)).

The microstructural transformation in the UFGB and UFG composite materials after annealing at $523 \mathrm{~K}$ is presented in Figure 6. At this temperature, drastic microstructural variations were observed in the UFGB (Figure 6(a)) and UFGCC (Figure 6(b)). In the UFGB (Figure 6(a)), grain coarsening was observed with a grain size above $2 \mu \mathrm{m}$. In the UFGCC (Figure 6(b)), a duplex type of microstructure was observed, with fully recrystallized grains of $800 \pm 200 \mathrm{~nm}$ at the $\mathrm{SiC}$ particle/matrix interface and coarser grains above 1.5 $\mu \mathrm{m}$ in the matrix region (away from coarse $\mathrm{SiC}$ particles). Plate-shaped stable precipitates $(\beta)$ were observed along the grain boundaries of coarse grains in the UFGB and UFGCC, as shown in Figures 6(a) and (b). The microstructure of the UFGFC shows recrystallized ultrafine grains of $800 \pm 100 \mathrm{~nm}$ (Figure 6(c)). The fine subgrains in the UFGNC [as observed at $473 \mathrm{~K}$ (Figure 5(d))] were fully recrystallized and formed UFG grains of $350 \pm 100 \mathrm{~nm}$ (Figure 6(d)). In addition to the recrystallization of grains, plateshaped precipitates were observed along the grain boundaries of UFGFC and UFGNC materials.

Figure 7 shows the microstructural details of annealed UFG materials at $573 \mathrm{~K}$. At this temperature, a dislocation-free microstructure with coarse grains $(4 \pm 1 \mu \mathrm{m})$ was observed in the UFGB (Figure 7(a)). Grain coarsening was also observed in the UFGCC $(3 \pm 1 \mu \mathrm{m})$ and UFGFC $(2 \pm 0.5 \mu \mathrm{m})$ (Figures 7(b) and (c)). In the UFGNC, fully recrystallized UFG grains of 

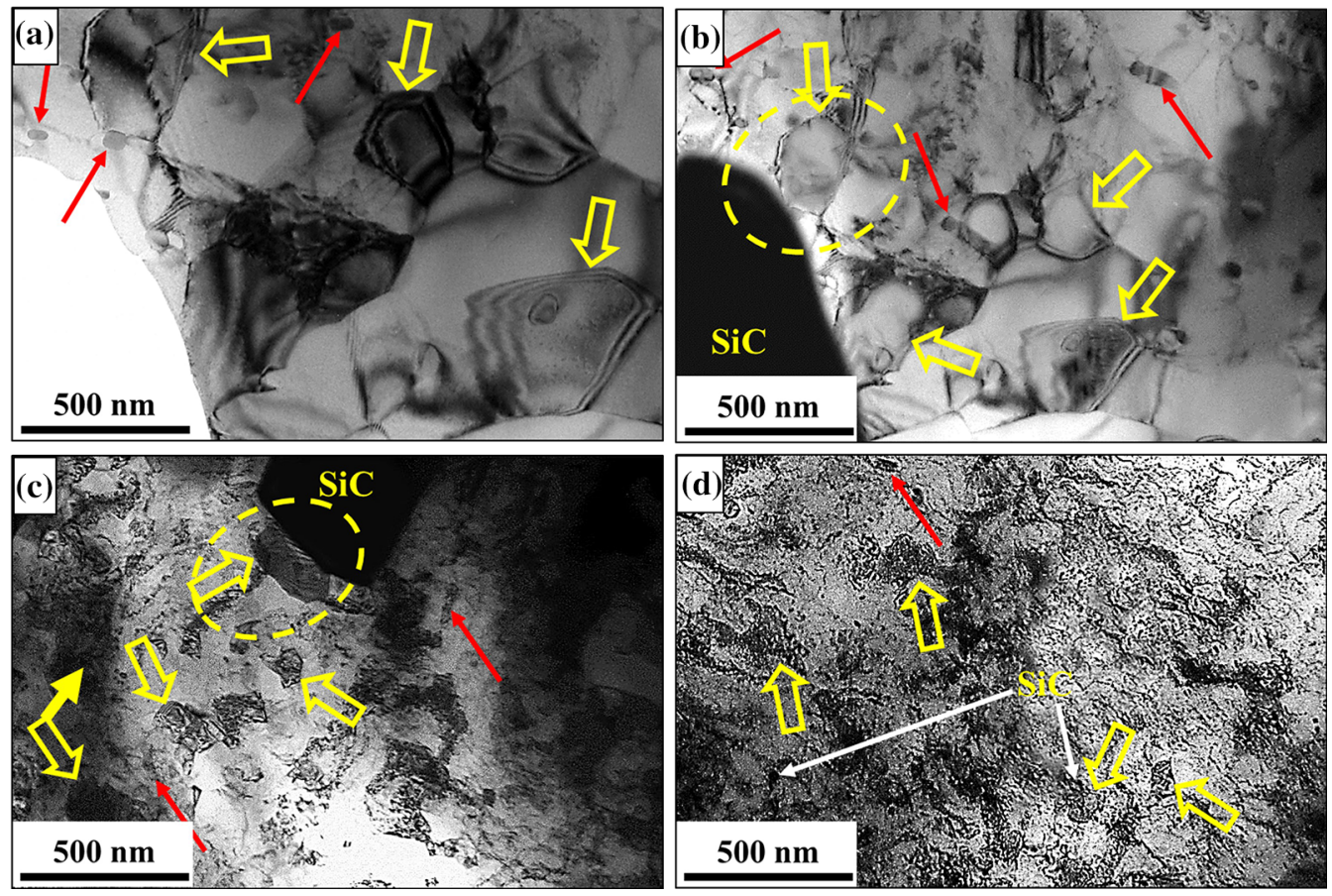

Fig. 5-TEM micrographs of (a) UFGB, (b) UFGCC, (c) UFGFC, and (d) UFGNC annealed at $473 \mathrm{~K}$.
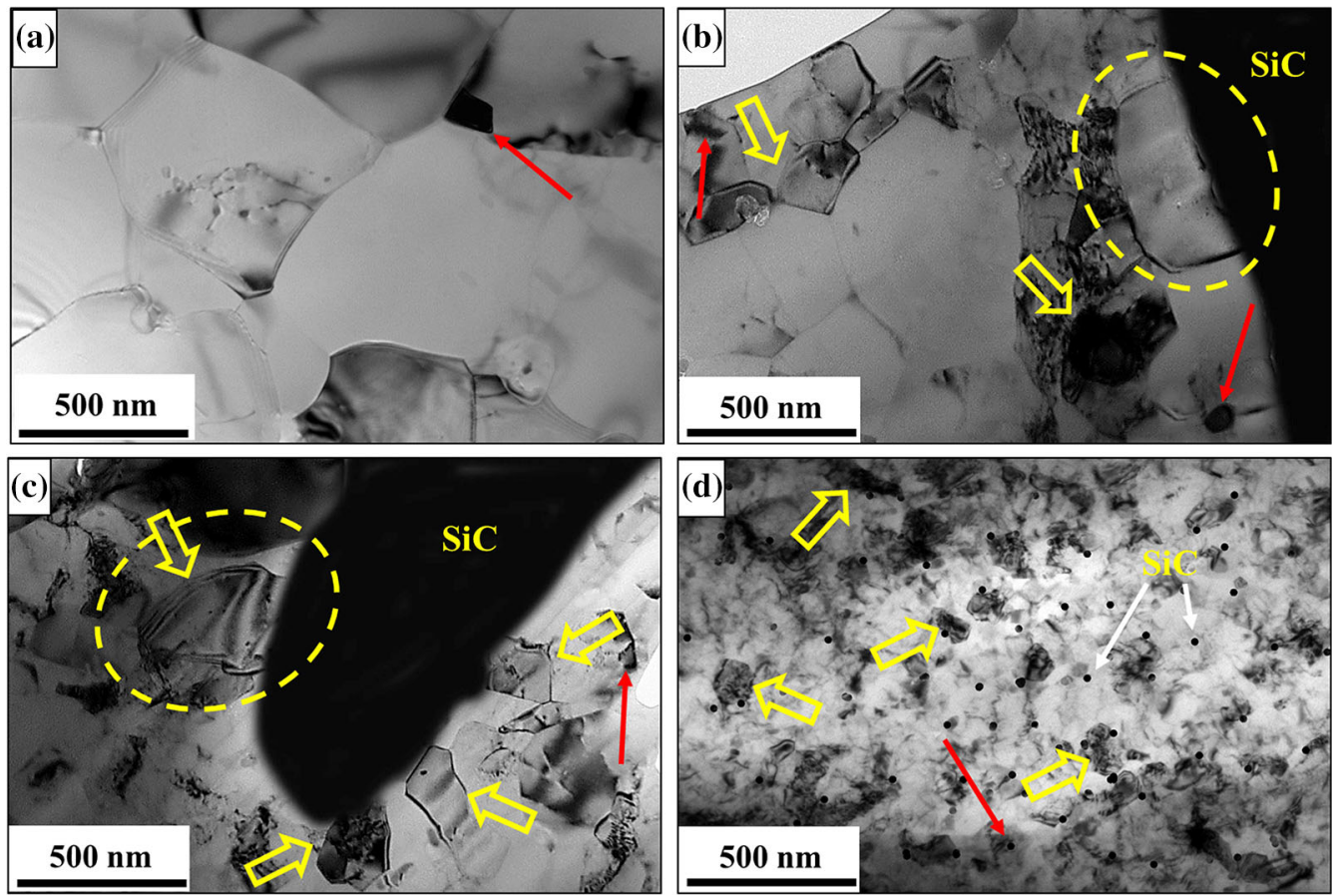

Fig. 6-TEM micrographs of (a) UFGB, (b) UFGCC, (c) UFGFC, and (d) UFGNC annealed at $523 \mathrm{~K}$.

$800 \pm 100 \mathrm{~nm}$ were observed, as shown in Figure 7(d). No evidence for the existence of precipitates was observed in any of the microstructures of UFG materials at this annealing temperature.

EBSD analysis was performed to examine the evolution of microstructure during annealing at temperatures ranging from $423 \mathrm{~K}$ to $573 \mathrm{~K}$. In EBSD images, RD and
TD represent the rolling and transverse directions, respectively, whereas the thickness direction (normal direction ND) is perpendicular to the paper (not shown in figures). EBSD micrographs of the UFGB, UFGCC, UFGFC, and UFGNC before annealing are shown in Figure 8 . The black and red lines in the microstructure indicate the location of high angle grain boundaries 

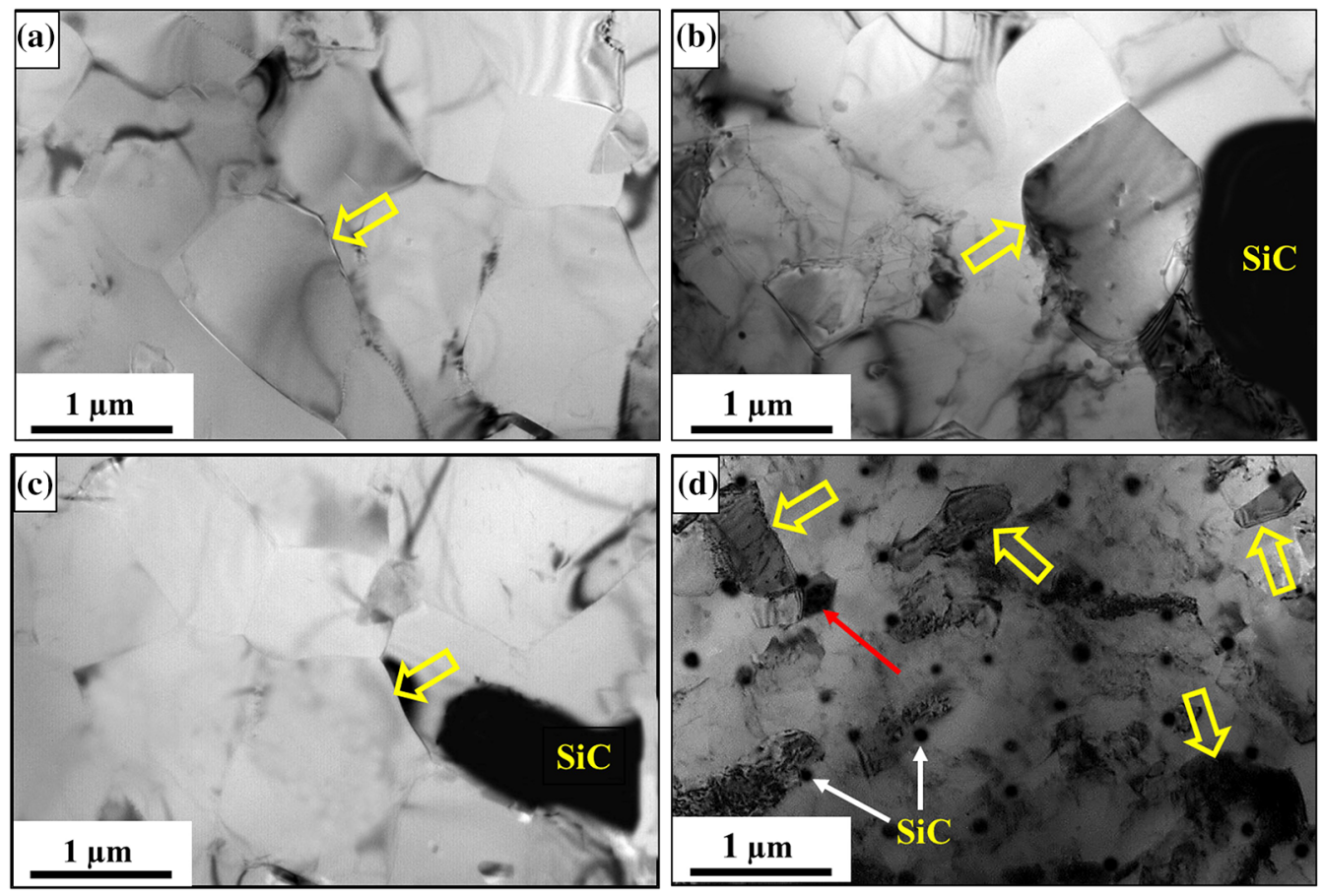

Fig. 7-TEM micrographs of (a) UFGB, (b) UFGCC, $(c)$ UFGFC, and $(d)$ UFGNC annealed at $573 \mathrm{~K}$.

(HAGB) $(\geq 15 \mathrm{deg}$ ) and low angle grain boundaries (LAGB) (2 deg through $15 \mathrm{deg}$ ), respectively. EBSD micrographs of the UFGB and UFG composite materials exhibit severely fragmented grains (Figure 8). It can be observed from the figure that the microstructure of all UFG materials is dominated by LAGBs (Figures 8(a) through (d)). In case of UFG composites, the fraction of LAGBs is increased with the decreasing $\mathrm{SiC}$ particle size, and these LAGB lines correspond to the dislocation substructures. In the case of the UFGCC (Figure 8(b)) and UFGFC (Figure 8(c)), the fraction of LAGBs in regions surrounding $\mathrm{SiC}$ particles is higher than that in the matrix region. A higher fraction of LAGBs was observed in the UFGNC (Figure 8(d)). A kernel average misorientation (KAM) analysis (with the help of EBSD data) was carried out to determine the extent of plastic deformation in UFG materials (Figure 8). KAM is used to assess the strain induced in the grains of the deformed materials. Recrystallized grains show low KAM values $(<1 \mathrm{deg})$, and deformed grains show high ( $>1 \mathrm{deg})$ KAM values. ${ }^{[35]}$ In the current study, KAM values of $1.6695 \mathrm{deg}, 2.4652 \mathrm{deg}$, $3.2274 \mathrm{deg}$, and $3.2671 \mathrm{deg}$ were obtained for the UFGB, UFGCC, UFGFC, and UFGNC, respectively. The higher ( $>1 \mathrm{deg}$ ) KAM values show highly strained grains in all UFG materials. With the decreasing $\mathrm{SiC}$ particle size from coarse to fine and then to nano, the KAM values increased. The UFGNC showed the highest KAM value compared to The UFGB, UFGCC, and UFGFC, which indicates that the microstructure possesses highly strained grains.

Figures 9, 10, 11 and 12 show the EBSD images of UFG materials subjected to annealing at different temperatures. At $423 \mathrm{~K}$ annealing, a drastic reduction in LAGBs was observed in the UFGB (Figure 9(a)) material compared to its nonannealed counterpart. This was due to the annihilation of LAGBs during the recovery process to form subgrain structures. In case of the UFGCC and UFGFC, the LAGBs in regions surrounding $\mathrm{SiC}$ particles were rearranged to nucleate subgrains (Figures 9(b) and (c)). However, the subgrains formed at a distance from the $\mathrm{SiC}$ particles showed the presence of clear HAGB. The UFGNC (Figure 9(d)) did not show much reduction in LAGBs. The distinct features of microstructural evolution occurred at 473 $\mathrm{K}$ annealing (Figure 10). The nucleation of equiaxed grains with HAGBs was apparent in the UFGB (Figure 10(a)) and UFGCC (Figure 10(b)). The PSN effect was clearly observed in regions surrounding $\mathrm{SiC}$ particles in both UFGCC and UFGFC (Figures 10(b) and (c)). The formation of subgrains with HAGBs was observed in the UFGNC (Figure 10(d)). Comparatively, annealing at $523 \mathrm{~K}$ resulted in significant microstructural changes in all UFG materials, as shown in Figure 11. The grain coarsening could be observed in the UFGB (Figure 11(a)) with almost all grains in HAGBs. Grains in the UFGB ranged from 1 to $6 \mu \mathrm{m}$. The LAGBs of the UFGCC and UFGFC were decreased substantially at this annealing temperature. Both the UFGCC and UFGFC exhibited duplex microstructure (Figure 11(b) and (c)). In the UFGCC, the microstructure contained PSN-based grains of $800 \pm 200 \mathrm{~nm}$ in the regions surrounding coarse $\mathrm{SiC}$ particles and coarser grains of $1.5 \pm 0.5 \mu \mathrm{m}$ in the matrix region, away from the $\mathrm{SiC}$ particles. Similarly, in the UFGFC, grains of $500 \pm 200 \mathrm{~nm}$ were observed in regions surrounding fine $\mathrm{SiC}$ particles, and grains of $900 \pm 100 \mathrm{~nm}$ were seen in the matrix region. The UFGNC microstructure (Figure 11(d)) showed recrystallized UFG grains of $350 \pm 100 \mathrm{~nm}$. Annealing at 573 

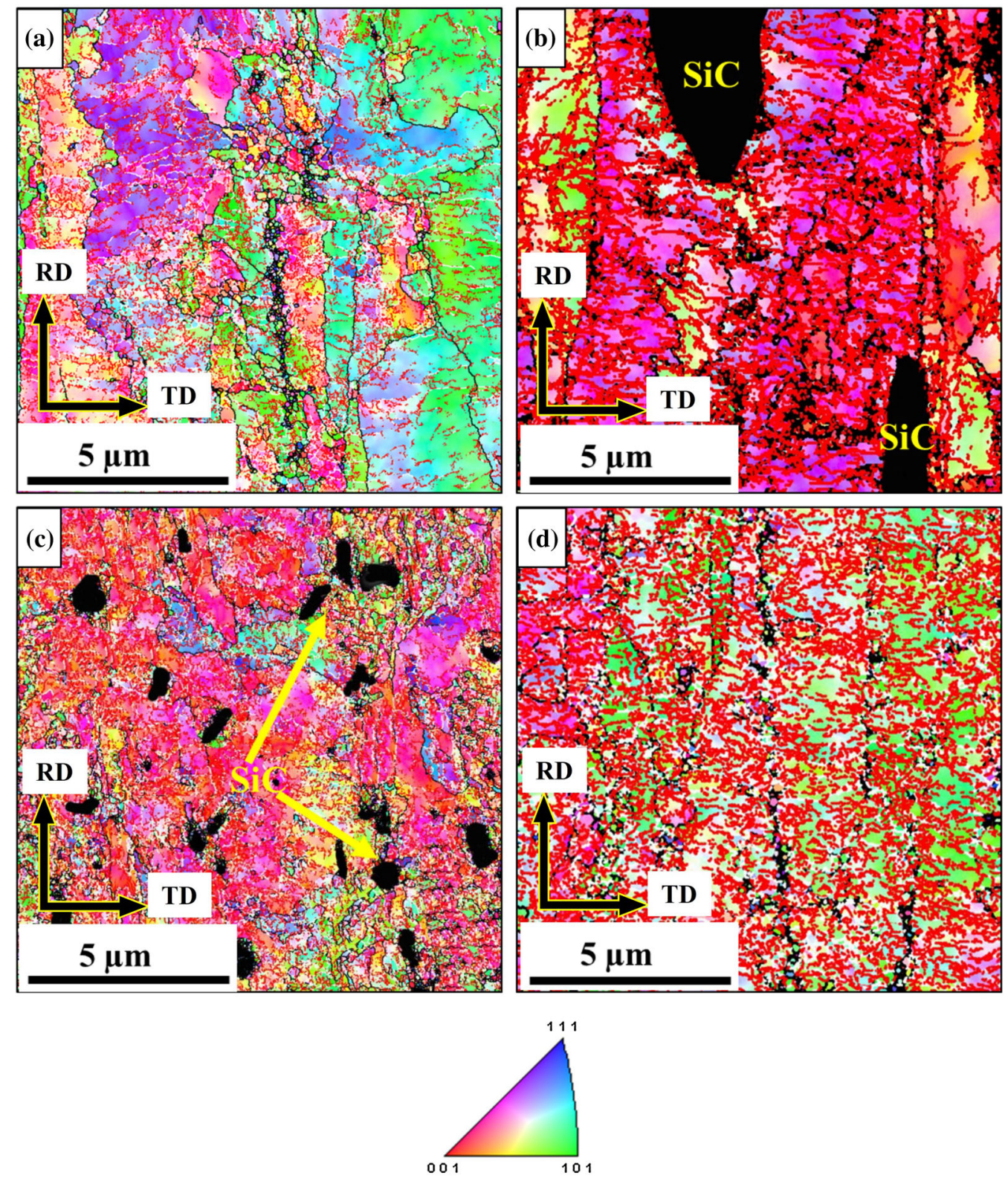

Fig. 8-EBSD images of (a) UFGB, (b) UFGCC, (c) UFGFC, and (d) UFGNC in the as-cryorolled conditions showing high dislocation density.

$\mathrm{K}$ further coarsened the grains in the UFGB (Figure 12(a)) in a range of $6 \pm 2 \mu \mathrm{m}$. A duplex microstructure was still observed in the UFGCC [2 $\mu \mathrm{m}$ grains in regions surrounding coarse $\mathrm{SiC}$ particles and 6 $\mu \mathrm{m}$ grains in the matrix region (Figure 12(b)] and UFGFC $[1 \mu \mathrm{m}$ grains in regions surrounding fine $\mathrm{SiC}$ particles and $2 \pm 1 \mu \mathrm{m}$ grains in the matrix region (Figure 12(c))]. At this annealing temperature, the UFGNC (Figure 12(d)) showed fully recrystallized UFG grains in the range of $600 \pm 150 \mathrm{~nm}$.

\section{Mechanical Properties of Annealed UFG Materials}

Table III presents the mechanical properties of UFG materials before and after annealing. Figure 13 shows the tensile test results of the UFGB and UFG composite materials annealed at a temperature range of $423 \mathrm{~K}$ to $573 \mathrm{~K}$. A higher strength (ultimate tensile strength (UTS)) was found in the UFGB and UFG composite materials compared to their annealed counterparts, as shown in Table III. Among all UFG materials, the UFGNC exhibited the maximum UTS (UFGB $=275$ $\pm 4 \mathrm{MPa}, \mathrm{UFGCC}=331 \pm 3 \mathrm{MPa}, \mathrm{UFGFC}=343$ $\pm 2 \mathrm{MPa}, \mathrm{UFGNC}=409 \pm 2 \mathrm{MPa}$ ). A small decrease in strength (UTS) along with a slight enhancement in ductility was observed at an annealing temperature of $423 \mathrm{~K}$ in the UFGB and UFG composites (Figures 13(a) through (d)). A gradual decrease in strength and increase in ductility of the UFGB and UFG composites was observed at $473 \mathrm{~K}$ annealing. At annealing temperatures of $523 \mathrm{~K}$ and $573 \mathrm{~K}$, a sudden drop in the strength and rise in ductility of the UFGB 

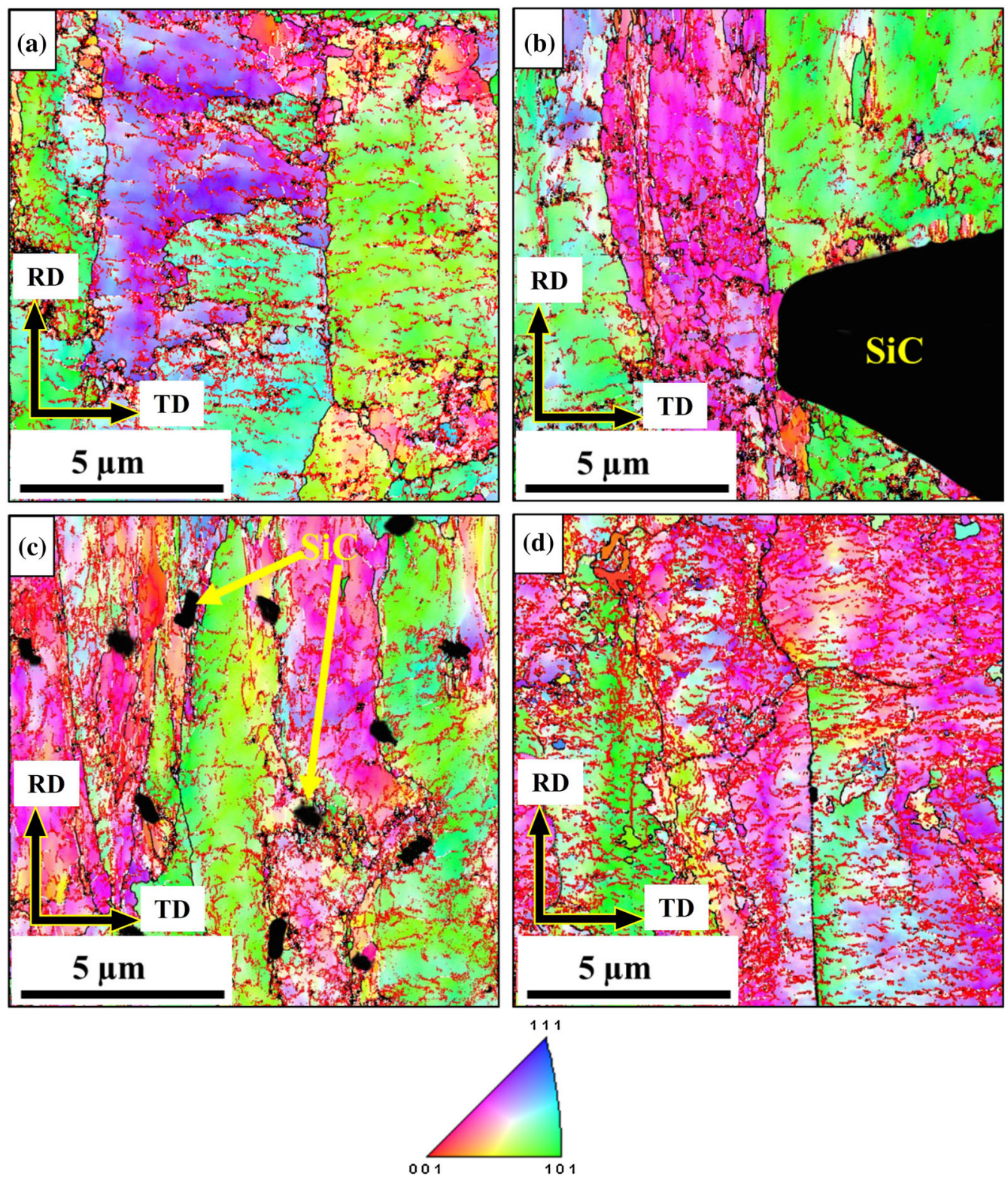

Fig. 9-EBSD images of (a) UFGB, (b) UFGCC, (c) UFGFC, and (d) UFGNC annealed at $423 \mathrm{~K}$.

and UFG composites was observed compared to the 473 $\mathrm{K}$ annealing temperature. On the other hand, no significant variations in strength and ductility were observed in all UFG materials at annealing temperatures of $523 \mathrm{~K}$ and $573 \mathrm{~K}$.

\section{DISCUSSION}

\section{A. Interface Characteristics and Precipitation Evolution}

The interface characteristics and precipitation evolution of the composites are discussed in this section. According to the literature, the interfaces of cast $\mathrm{Al} / \mathrm{SiC}$ composites often show the formation of secondary compounds such as $\mathrm{Al}_{4} \mathrm{C}_{3} \cdot{ }^{[36]}$ The formation of secondary compounds is attributed to the interdiffusion of $\mathrm{Al}$ and $\mathrm{SiC}$ particles. However, evidence for such
$\mathrm{Al}_{4} \mathrm{C}_{3}$-type intermetallic compound formation has not been observed in the current study (XRD (Figure 1) and TEM (Figure 3)). The possible reasons behind the nonoccurrence of secondary compounds (such as $\mathrm{Al}_{4} \mathrm{C}_{3}$ ) are explained below.

In the current study, the maximum temperature raised during composite casting was $973 \mathrm{~K}$ for a short period of time (10 minutes). During stir-casting, $\mathrm{SiC}$ particles were dispersed in liquid aluminum alloy due to the stirring action. The liquid aluminum diffused into $\mathrm{SiC}$ at $973 \mathrm{~K}$. This diffusion of $\mathrm{Al}$ in $\mathrm{SiC}$ during stir-casting was not sufficient to form interdiffusional compounds (such as $\mathrm{Al}_{4} \mathrm{C}_{3}$ ) because of the much lower duration of holding time (10 minutes) during casting. Secondary compound $\left(\mathrm{Al}_{4} \mathrm{C}_{3}\right)$ formation in the $\mathrm{Al}-\mathrm{SiC}$ system often occurs at a casting temperature of $973 \mathrm{~K}$ with a longer holding time $(\approx 1$ hour $){ }^{[37-43]}$ The experimental outcomes of the 

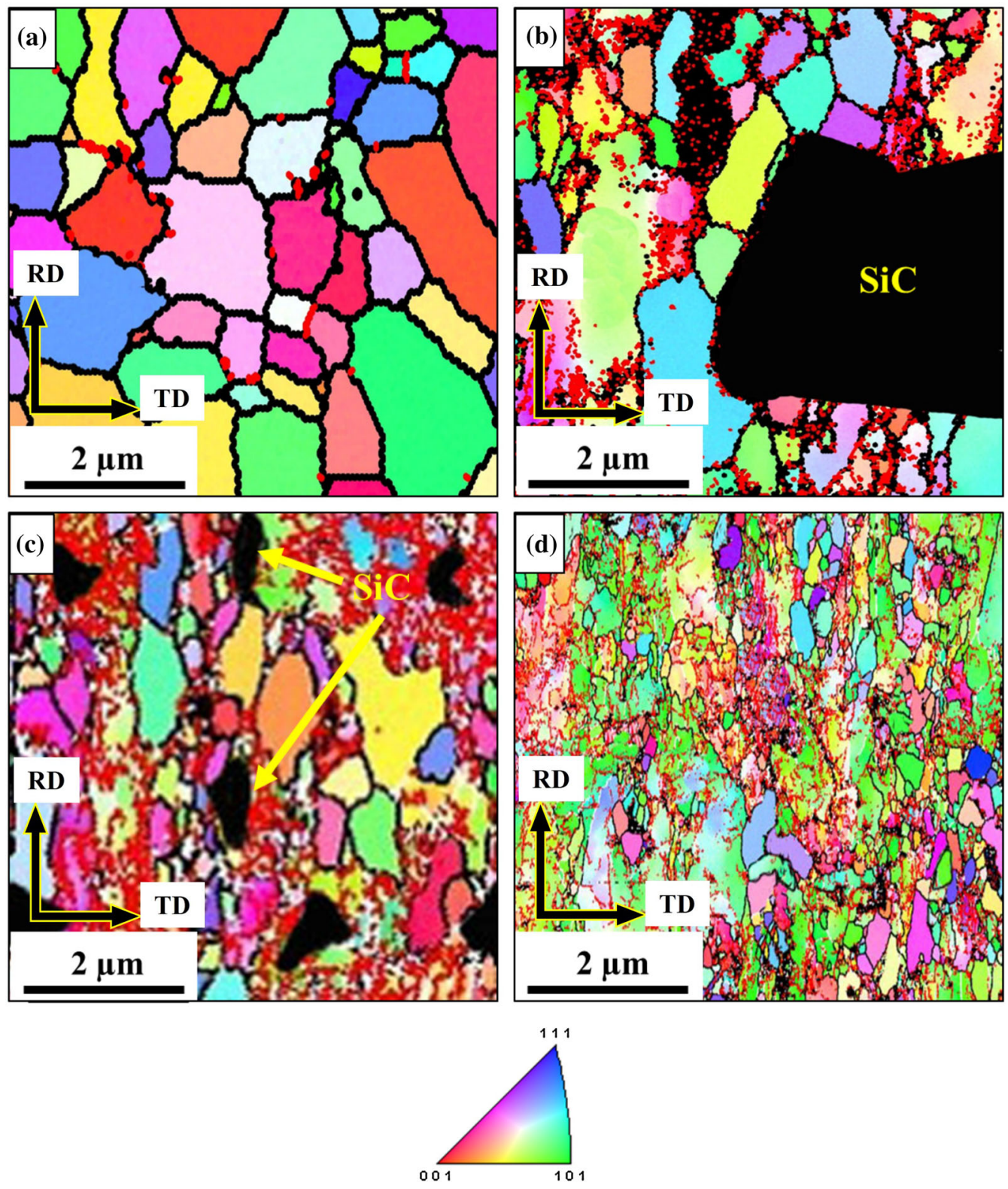

Fig. 10-EBSD images of (a) UFGB, (b) UFGCC, $(c)$ UFGFC, and (d) UFGNC annealed at $473 \mathrm{~K}$.

present study are consistent with the results obtained by Tham et al. ${ }^{[44]}$ These UFG microstructures without any secondary compounds were used to further examine precipitation evolution.

The precipitation evolution sequence and kinetics were analyzed when the UFGB, UFGCC, UFGFC, and UFGNC materials were annealed at various temperatures ranging from $423 \mathrm{~K}$ to $573 \mathrm{~K}$. The well-explored precipitation sequence of the AA6063 alloy presented below was used to describe the evolution of precipitates in UFGB, UFGCC, UFGFC, and UFGNC materials at various annealing temperatures in the present study. ${ }^{[34,45]}$ The precipitation sequence of the solution-treated AA6063 alloy is as follows:

SSSS (supersaturated solid solution) $\alpha \rightarrow$ GP zones $\rightarrow \beta^{\prime \prime} \rightarrow \beta^{\prime} \rightarrow \beta$
The solution treatment of the base alloy (AA6063 alloy) resulted in the complete dissolution of solute atoms into the aluminum matrix and their retainment in a metastable state. Cryorolling the base alloy and composites with varying reinforcement particle sizes at a strain of 2.4 retained the solute atoms in a metastable state (Figure 3). As the samples were rolled at cryogenic temperature, they were not supplied with ample energy to evolve the precipitates from solid solution. The spherically shaped GP zones were formed at an annealing temperature of $423 \mathrm{~K}$ (Figures 4(a) through (d); red arrows). GP zones are clusters of $\mathrm{Mg}$ and $\mathrm{Si}$ and are clearly visible in the UFGB and UFG composite materials. The GP zones were seen along the boundaries of dislocation cell structures in the UFGFC and UFGNC, as the matrix region was flooded with 

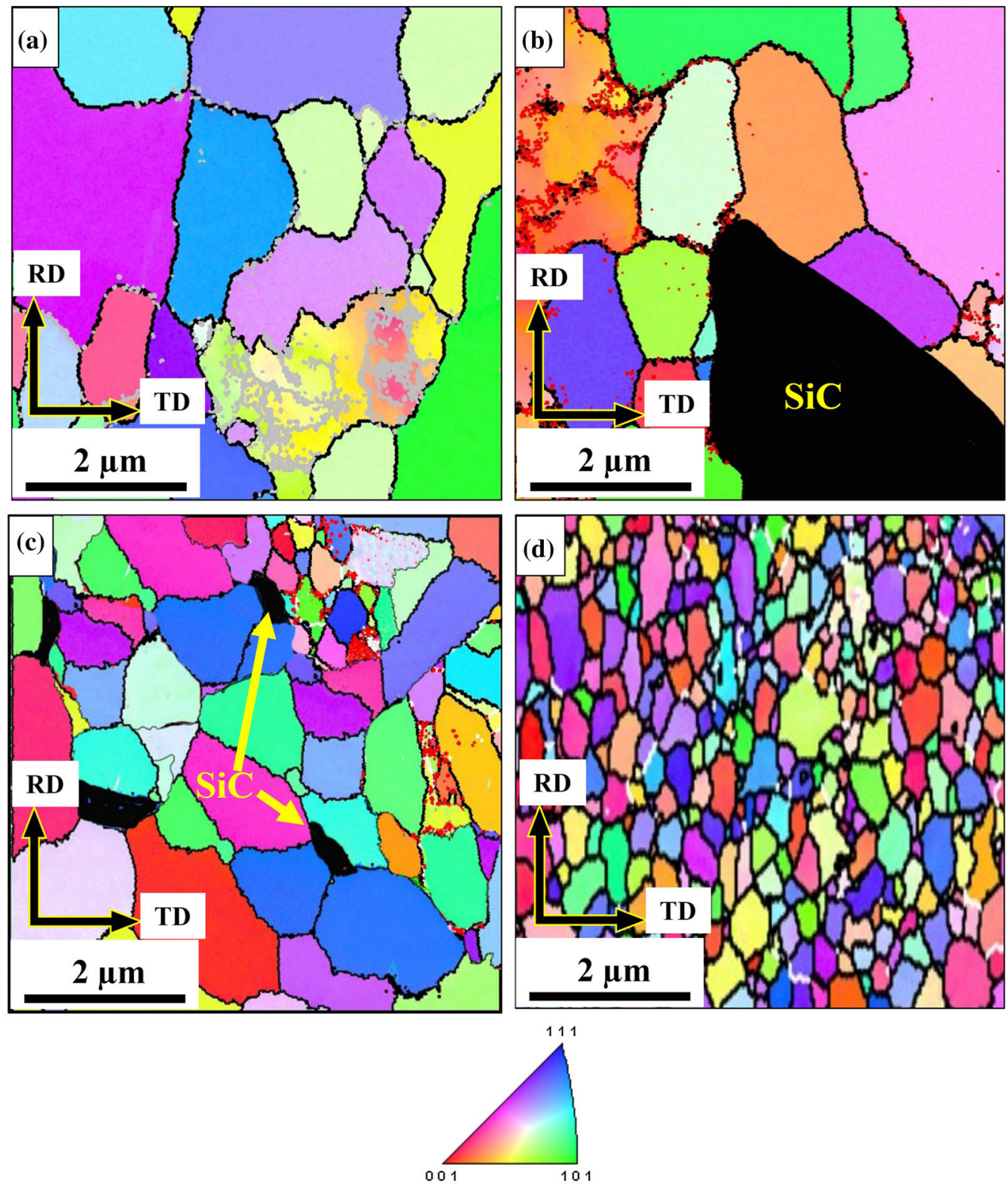

Fig. 11-EBSD images of $(a)$ UFGB, $(b)$ UFGCC, $(c)$ UFGFC, and $(d)$ UFGNC annealed at $523 \mathrm{~K}$.

dislocation cells. Few needle-shaped precipitates $\left(\beta^{\prime \prime}\right)$ were observed along with rod-shaped precipitates $\left(\beta^{\prime}\right)$ at $473 \mathrm{~K}$ annealing in all UFG materials. These rod-shaped precipitates pinned the boundaries of the ultrafine grains and are evident in Figures 5(a) through (d)). The rod-shaped $\left(\beta^{\prime}\right)$ precipitates were dissolved above $473 \mathrm{~K}$ annealing, and the stable plate-shaped precipitates $(\beta)$ were formed at $523 \mathrm{~K}$ annealing. The plate-shaped precipitates were seen along the grain boundaries in the UFGB and UFG composites (Figures 6(a) through (d)). At $573 \mathrm{~K}$ annealing, plate-shaped precipitates were also observed in all UFG materials (Figures 7(a) through (d)), but the intensity (quantity) of these precipitates was diminished (quantified based on the TEM images of all the UFG materials). Urrutia et al. ${ }^{[46]}$ examined the age-hardening behavior of $\mathrm{Al}-\mathrm{Mg}-\mathrm{Si}$ alloy and observed the formation of $\beta^{\prime}$ precipitate at $523 \mathrm{~K}$ for 30 minutes of aging and $\beta$ precipitate at $523 \mathrm{~K}$ for 8 hours of aging. However, in the current study, a similar evolution of various precipitation phases was observed within $523 \mathrm{~K}$ in all UFGB and UFG composite materials, even at 1 hour of annealing treatment (much less annealing time compared to 8 hours). This faster precipitation kinetic process was due to the presence of high internal stored energy during cryorolling in the UFGB and UFG composite materials, which provided additional energy for the evolution of precipitates with the increasing annealing temperature.

\section{B. Thermal Stability and Grain Growth}

The annealing of the UFGB and UFG composites led to recovery, recrystallization, and grain growth during microstructural evolution. The varying $\mathrm{SiC}$ particle sizes 

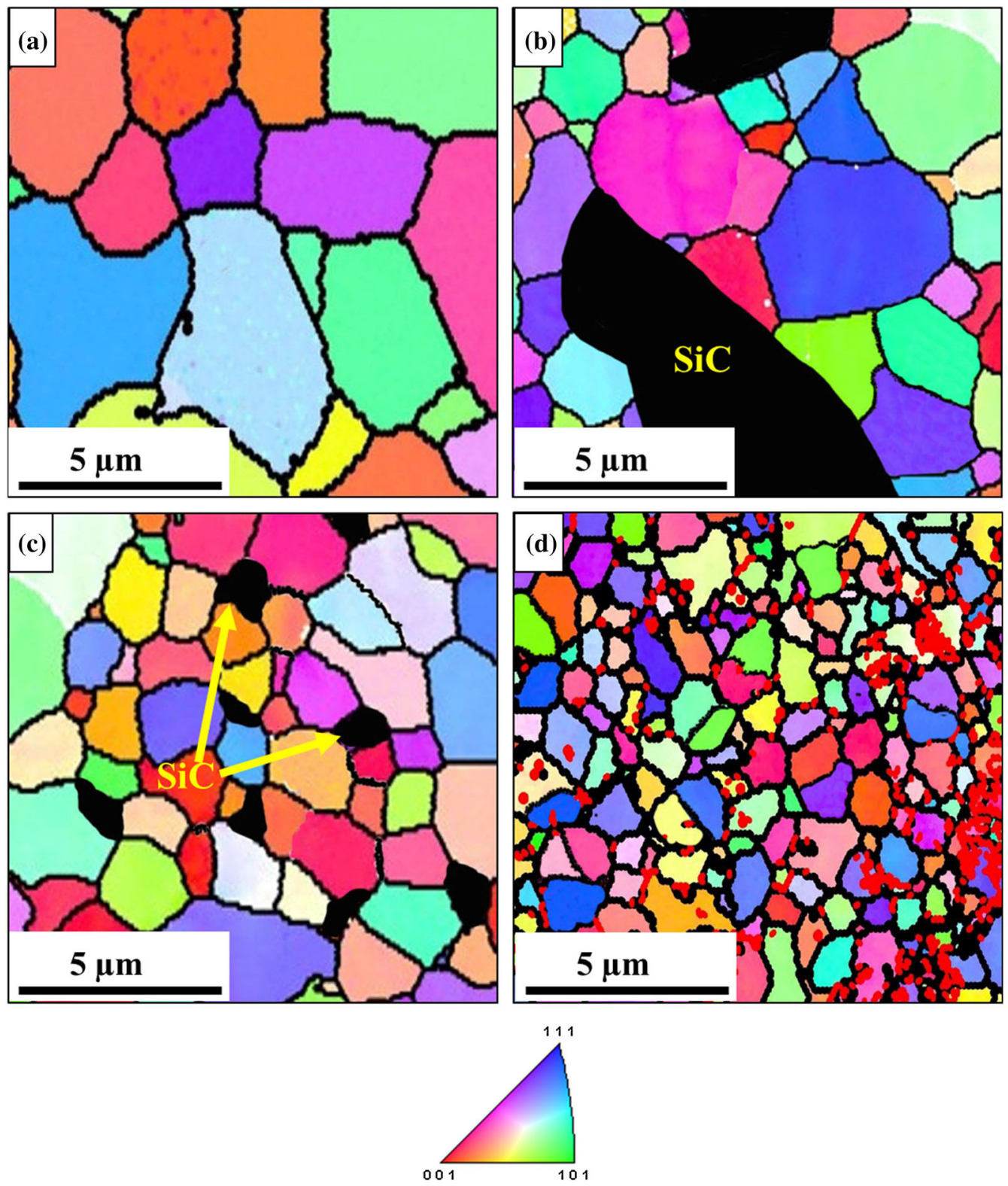

Fig. 12-EBSD images of $(a)$ UFGB, $(b)$ UFGCC, $(c)$ UFGFC, and $(d)$ UFGNC annealed at $573 \mathrm{~K}$.

played an important role in the thermal stability and grain growth phenomenon. Reinforcement particle size influenced the recrystallization, grain growth, and thermal stability in two dominant ways: particle-stimulated nucleation and grain growth retardation (pinning of $\mathrm{SiC}$ particles to retard grain growth).

\section{Particle-Stimulated Nucleation}

It is evident from the authors' previous work ${ }^{[16]}$ that UFG composite materials possess a high dislocation density. The accumulation of dislocation is due to (i) severe deformation of the matrix alloy and (ii) mismatch in the thermal expansion coefficient of the matrix alloy and $\mathrm{SiC}$ particles. This high density of dislocation in regions surrounding $\mathrm{SiC}$ particles creates high strain in the vicinity of $\mathrm{SiC}$ particles and acts as an energy pocket. When the UFGCC and UFGFC were annealed at 423
$\mathrm{K}$, the high strain energy and annealing temperature facilitated the driving force for the dislocations accumulated in the vicinity of $\mathrm{SiC}$ particles to nucleate and form nano/ultrafine grains in regions surrounding $\mathrm{SiC}$ particles (Figure 4(b) and (c)). This is also called particle-stimulated nucleation (PSN). In case of the UFGNC (Figure 4(d)) at $423 \mathrm{~K}$ annealing, dislocation cell formation was observed, but there was no evidence of the nucleation of nano/ultrafine grains at the nano-SiC particles. This result follows the criterion of minimum particle size, which should be $\geq 1 \mu \mathrm{m}$ for nucleation of grains developed via PSN as proposed by Humphrey et al. ${ }^{[4]}$ As per the TEM investigation, nano-SiC particles were observed to pin the dislocation cell boundaries in the UFGNC with no sign of PSN (Figures 4, 5, 6, and 7). At an annealing temperature of $473 \mathrm{~K}$, the unrecrystallized nano/ultrafine grains evolved 


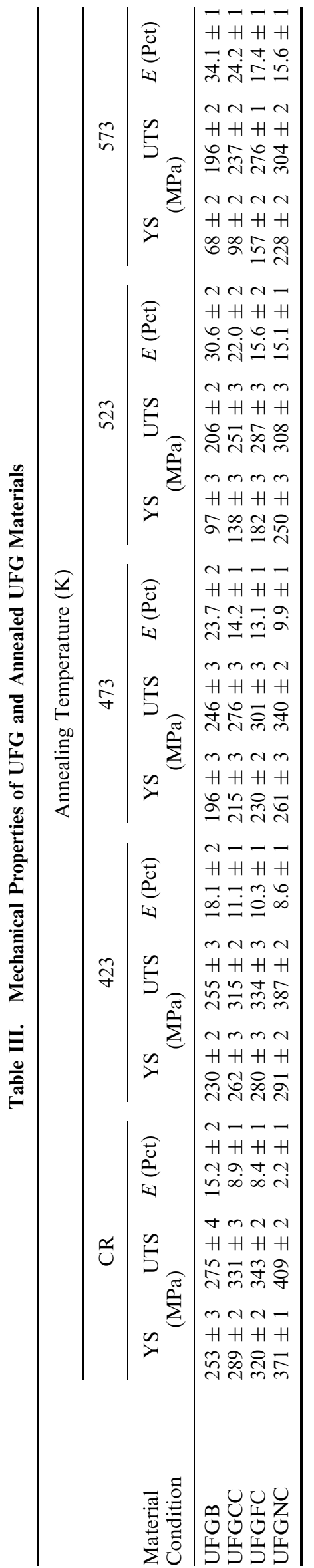

and subsequently formed recrystallized UFG grains with clear boundaries near the coarse and fine $\mathrm{SiC}$ particles in the UFGCC and UFGFC composites (Figures 5(b) and (c)). When the UFGCC and UFGFC composites were annealed at $523 \mathrm{~K}$, the strain energy accumulated near the $\mathrm{SiC}$ particles due to cryorolling completely recovered and consequently formed fully recrystallized ultrafine grains near the $\mathrm{SiC}$ particles (Figures 6(b) and (c)). At this annealing temperature in the UFGNC, nanoparticles were pinned along the boundaries of UFG grains (Figure 6(d)). At an annealing temperature of $573 \mathrm{~K}$, the recrystallized UFG grains (at the periphery of coarse and fine $\mathrm{SiC}$ particles) were further developed and subsequently formed grains in the range of 2 and $1 \mu \mathrm{m}$ in regions surrounding the coarse and fine $\mathrm{SiC}$ particles, respectively (Figures 7(b) and (c)).

\section{Pinning of SiC Particles and Grain Growth}

The recovery and recrystallization phenomena during grain growth are highly affected by the presence of $\mathrm{SiC}$ particles in the matrix. The pinning force exerted by the $\mathrm{SiC}$ particles and the interparticular distance between $\mathrm{SiC}$ particles played a vital role in recovery and recrystallization phenomena during grain growth. The pinning force exerted by the $\mathrm{SiC}$ particles and the interparticular distance between the $\mathrm{SiC}$ particles are given by Eqs. [3] and [4], respectively. ${ }^{[16]}$

$$
\begin{gathered}
P=\frac{3 \gamma V_{p}}{2 d_{p}} \\
\lambda=d_{p}\left[\frac{\pi}{6 V_{p}}-\frac{2}{3}\right]^{1 / 2},
\end{gathered}
$$

where $P$ is the pinning force, $V_{p}$ is the volume percentage of $\mathrm{SiC}$ particulates, $\gamma$ is the interfacial energy, $\lambda$ is the interparticular distance, and $d_{p}$ is the particle size. It is clearly decipherable from Eq. [3] that the pinning force $P$ is inversely proportional to the particle size $d_{p}$, whereas the interparticular distance $\lambda$ (Eq. [4]) is directly proportional to the particle size $d_{p}$. The values of interparticular distance provided in Table II show that, with the reduction in $\mathrm{SiC}$ particle size, interparticular distance has decreased. This is because, as the $\mathrm{SiC}$ particle size decreases (for the same wt pct), the number of $\mathrm{SiC}$ particles increases. Therefore, increased numbers of $\mathrm{SiC}$ particles were observed pinning along the grain boundaries of the UFGNC when compared to the UFGFC and UFGCC. The increase in the number of $\mathrm{SiC}$ particles with a decrease in $\mathrm{SiC}$ particle size further increased the pinning action along the grain boundaries, which ultimately increased the pinning force. This increased pinning action and reduced interparticular distance of nano-SiC particles in the UFGNC composite refined the grain structure to a significant extent (Figures 8 through 12).

During the annealing treatment of the UFGB and UFG composites, their microstructures underwent recovery, recrystallization, and grain growth. These changes were due to the release of internal stored energy 


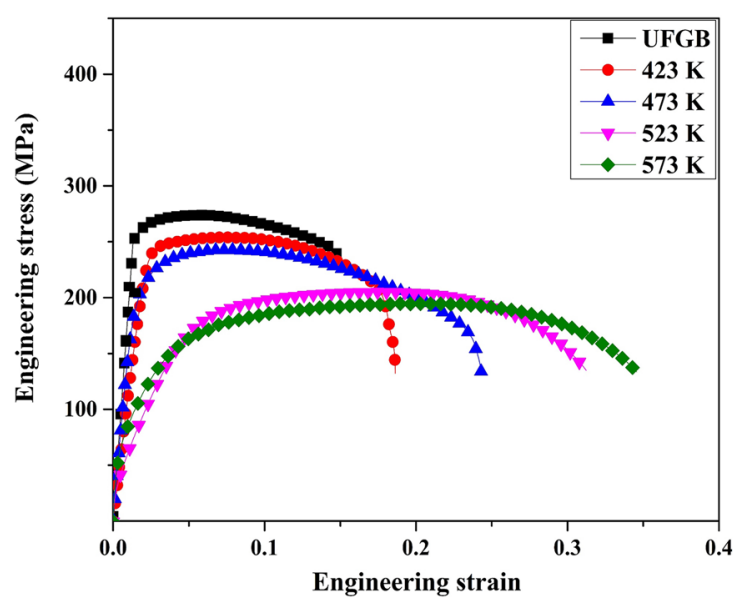

(a)

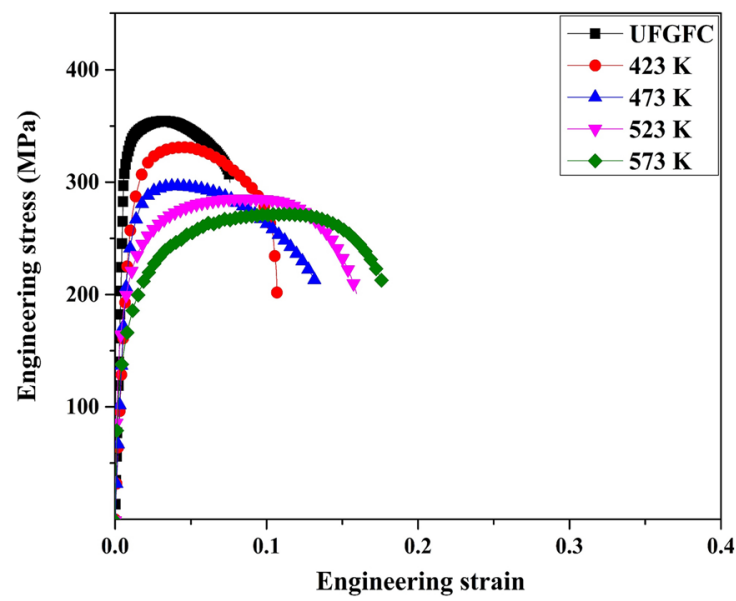

(c)

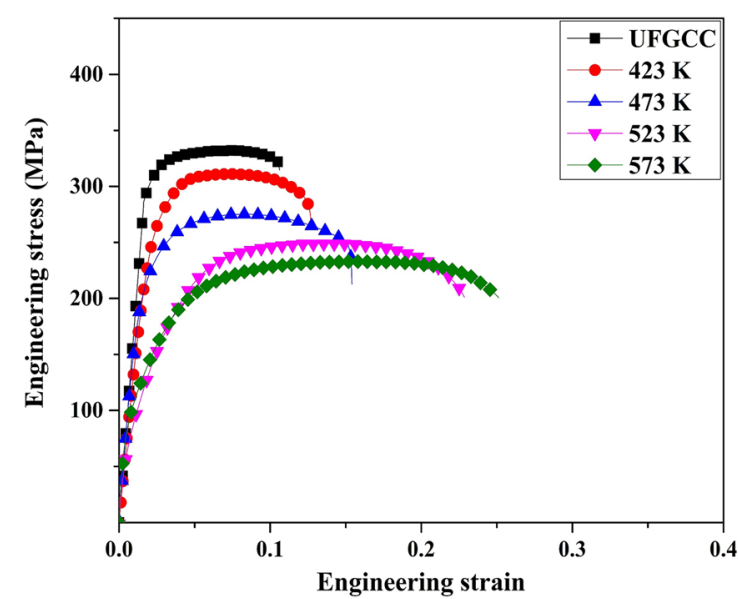

(b)

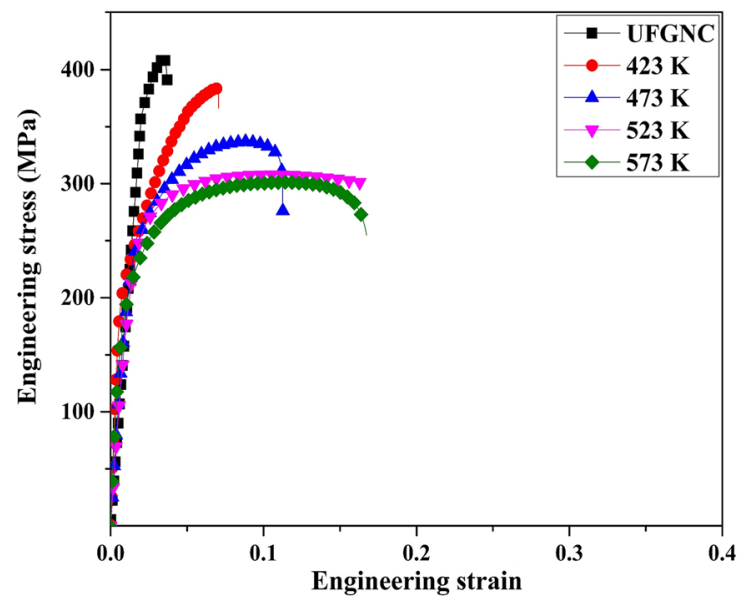

(d)

Fig. 13-Engineering stress-strain curves of $(a)$ UFGB, (b) UFGCC, $(c)$ UFGFC, and (d) UFGNC both in the as-cryorolled and annealed conditions (at $423 \mathrm{~K}, 473 \mathrm{~K}, 523 \mathrm{~K}$ and $573 \mathrm{~K}$ ).

and the additional energy provided (in terms of heat energy) during the post-cryorolling annealing process. The driving force provided by the annealing temperature to release the stored internal energy is called static recovery. Subsequent to the recovery process, the microstructure led to the formation of recrystallized ultrafine grains in the UFGB and UFG composites (Figures 4 and 10). Figure 14 schematically represents the mechanism of grain growth at different annealing temperatures. The combined action of precipitates and $\mathrm{SiC}$ particles influenced the recrystallization and grain growth phenomena in the UFGCC, UFGFC, and UFGNC composite materials (Figures 14(a) through (d)).

The influence of annealing temperature on the grain growth kinetics of the UFGB, UFGCC, UFGFC, and UFGNC composite materials was studied in detail using Eq. $[5],{ }^{[13]}$ and the results are presented in Figures 15 and 16.

$$
D^{n}-D_{0}^{n}=k_{0} t \exp \left(-\frac{Q}{R T}\right)
$$

where $D$ represents the average grain size, $D_{\mathrm{o}}$ denotes unrecrystallized grain size, $t$ stands for the annealing time, $n$ represents the grain growth exponent $(n=8)$, $k_{\mathrm{o}}$ is a time- and temperature-independent constant, $R$ is the ideal gas constant, $T$ denotes the material temperature, and $Q$ is the required activation energy for grain growth initiation. The grain growth exponent $n$ depends on the presence of second-phase particles (SiC) or alloying elements in the solid solution, which offers resistance to grain boundary migration. ${ }^{[48]}$ Equation [5] is converted into a linear form by taking the logarithm on both sides.

$$
\ln \left(D^{n}-D_{0}^{n}\right)=\ln \left(k_{0}\right)+\ln (t)-\frac{Q}{R T}
$$

Equation [6] is a linear equation with a slope of $-Q / R$. A semi-logarithmic plot between $\left(D^{n}-D_{0}^{n}\right)$ and $1 / T$ is used to determine the required activation energy for grain growth in the UFGB, UFGCC, UFGFC, and UFGNC composite materials. Figure 16 represents the variation in grain growth activation energy required for UFGB and UFG composite materials. The activation energy required by the UFGB and UFG composites at low temperatures (grain growth below $573 \mathrm{~K}$ ) signifies the energy required to form fully recrystallized ultrafine grains from the severely strained microstructure. 
However, the activation energy necessary at higher temperatures (grain growth above $573 \mathrm{~K}$ ) represents the energy required for grain growth from the UFG regime to the coarse microstructure. Lower activation energy is observed in the UFGNC $(20.25 \mathrm{~kJ} / \mathrm{mol})$ in the low-temperature zone compared to the UFGFC $(23.95 \mathrm{~kJ} / \mathrm{mol})$, UFGCC $(34.78 \mathrm{~kJ} / \mathrm{mol})$, and UFGB $(42.73 \mathrm{~kJ} / \mathrm{mol})$. This is attributed to the internal stored energy and high dislocation density of the UFGNC, which make the microstructure highly unstable. This unstable microstructure of the UFGNC, however, requires very low activation energy to recrystallize into a strain-free equiaxed microstructure. With the increasing particle size from nano to fine and then to coarse, the density of the ill-defined diffused grain boundaries along with the dislocation density decreased, which subsequently increased the activation energy required for grain growth. The grain growth activation energy of UFG composites $(\mathrm{UFGNC}=250 \mathrm{~kJ} / \mathrm{mol}, \mathrm{UFGFC}=189.1$ $\mathrm{kJ} / \mathrm{mol}$, and $\mathrm{UFGCC}=155.67 \mathrm{~kJ} / \mathrm{mol}$ ) increased significantly at higher annealing temperatures $(623 \mathrm{~K}$ to $673 \mathrm{~K})$ compared to UFGB $(121.62 \mathrm{~kJ} / \mathrm{mol})$. The varying reinforcement sizes of the $\mathrm{SiC}$ particles have a significant effect in increasing the activation energy for grain growth. Among the UFG composites, UFGNC $(250 \mathrm{~kJ} / \mathrm{mol})$ has the highest activation energy for grain growth. At higher temperatures, in the present case, the activation energy of UFGNC was even higher than the activation energy reported by $\mathrm{Niu}$ et al. $(242 \mathrm{~kJ} / \mathrm{mol})$ and other researchers. ${ }^{[48,49]}$ The probable reason for holding higher activation energy in the UFGNC compared to the UFGFC and UFGCC is the higher order of pinning action, as more fraction of nano-SiC particles are available at the grain boundaries of the UFGNC material. The pinning action of nano-SiC particles prevents grain boundary migration and retains the microstructure in the UFG regime, which is evident from the TEM and EBSD micrographs of the UFGNC, as shown in Figures 7 and 12.

The evolution of grain growth can also be observed from EBSD micrographs at different annealing temperatures. Annealing at $573 \mathrm{~K}$ led to grain growth (Figure 12). The grains in the UFGNC were thermally stable up to $573 \mathrm{~K}$ and located in the ultrafine grain regime. However, the UFGCC and UFGFC were thermally stable at $473 \mathrm{~K}$ and $523 \mathrm{~K}$, respectively. The coarsening of ultrafine grains was observed in the UFGFC, UFGCC, and UFGB at $573 \mathrm{~K}$. A duplex microstructure was observed at $573 \mathrm{~K}$ in both the UFGCC and UFGFC, with grain sizes of $6 \pm 2 \mu \mathrm{m}$ and $3 \pm 1 \mu \mathrm{m}$, respectively. This abnormal grain growth in the microstructure could be ascribed to (i) completion of recrystallization or (ii) ineffective grain boundary pinning by precipitates (due to the occurrence of coarsening of precipitates) and $\mathrm{SiC}$ particles. As stated above, the precipitation started above $423 \mathrm{~K}$ and increased up to $573 \mathrm{~K}$ of annealing temperature. These precipitates pinned the grain boundaries during annealing temperatures of $423 \mathrm{~K}$ to $573 \mathrm{~K}$. At higher annealing temperatures, coarsening of precipitates occurred, which weakened the pinning force along the grain boundaries and resulted in grain boundary migration. Therefore, the rate of recrystallization was higher near these precipitates, and hence, grain growth occurred in this area. Although increasing the annealing temperature weakened the pinning action of precipitates along the grain boundaries, in the UFGCC and UFGFC composites, the pinning force exerted by coarse and fine $\mathrm{SiC}$ particles remained the same along grain boundaries, thereby retarding the grain growth along $\mathrm{SiC}$ particles. This hindrance in grain growth along $\mathrm{SiC}$ particles provided a duplex microstructure in the UFGCC and UFGFC, with smaller grains along $\mathrm{SiC}$ particles and larger grains away from $\mathrm{SiC}$ particles, consequently exhibiting abnormal grain growth. Similar abnormal grain growth was observed in the UFGB up to a temperature of $523 \mathrm{~K}$, and then the grains were nearly equiaxed at $573 \mathrm{~K}$.

\section{Influence of Annealing on Mechanical Properties}

The impact of annealing temperatures on the strength and ductility variation of the UFGB, UFGCC, UFGFC, and UFGNC materials has been established in this section with the detailed underlying mechanism (Figure 13). The strength of the annealed UFGB and UFG composites was observed to be less than that of their nonannealed counterparts (Figure 13).

The UFGB and UFG composites showed a small reduction of approximately $5 \pm 1.6$ pct in strength when annealed at $423 \mathrm{~K}$. At this annealing temperature, the dislocation density was reduced in the UFGB and UFG composite materials (Figure 2), and simultaneous precipitation of GP zones was observed in the matrix. The fine GP zone precipitates, along with $\mathrm{SiC}$ particles, hindered the dislocation movement and grain boundary migration and thereby assisted in maintaining the strength of the UFGB and UFG composite materials. At the same temperature, subgrains were formed by the annihilation of dislocations, which aided in improving the strength of UFG materials by grain boundary strengthening. Therefore, at this annealing temperature, the cumulative effect of grain boundary strengthening and precipitation strengthening helped retain the strength of the UFGB, UFGCC, UFGFC, and UFGNC materials. Annealing at $423 \mathrm{~K}$ resulted in the formation of the UFG microstructure. These extremely fine grains, $\mathrm{SiC}$ particles (coarse, fine, and nano) and GP zone precipitates together actively hindered the dislocation mobility by grain boundaries and pinning action. As a result, the ductility of the UFGB and UFG composite materials did not show much improvement.

At an annealing temperature of $473 \mathrm{~K}$, the recrystallization continued along with the increased rate of precipitation in all UFG materials. An overall reduction of approximately $13.5 \pm 3$ pct in strength was observed in UFG materials compared to their nonannealed counterparts. The decrease in strength of the UFGCC, UFGFC, and UFGNC was due to the simultaneous action of (i) softening due to reduced dislocation density and increased grain boundary area and (ii) strengthening due to the formation of $\beta^{\prime \prime}$ precipitates, which provided the highest hardening effect in the AA6063 matrix alloy compared to other intermediate 


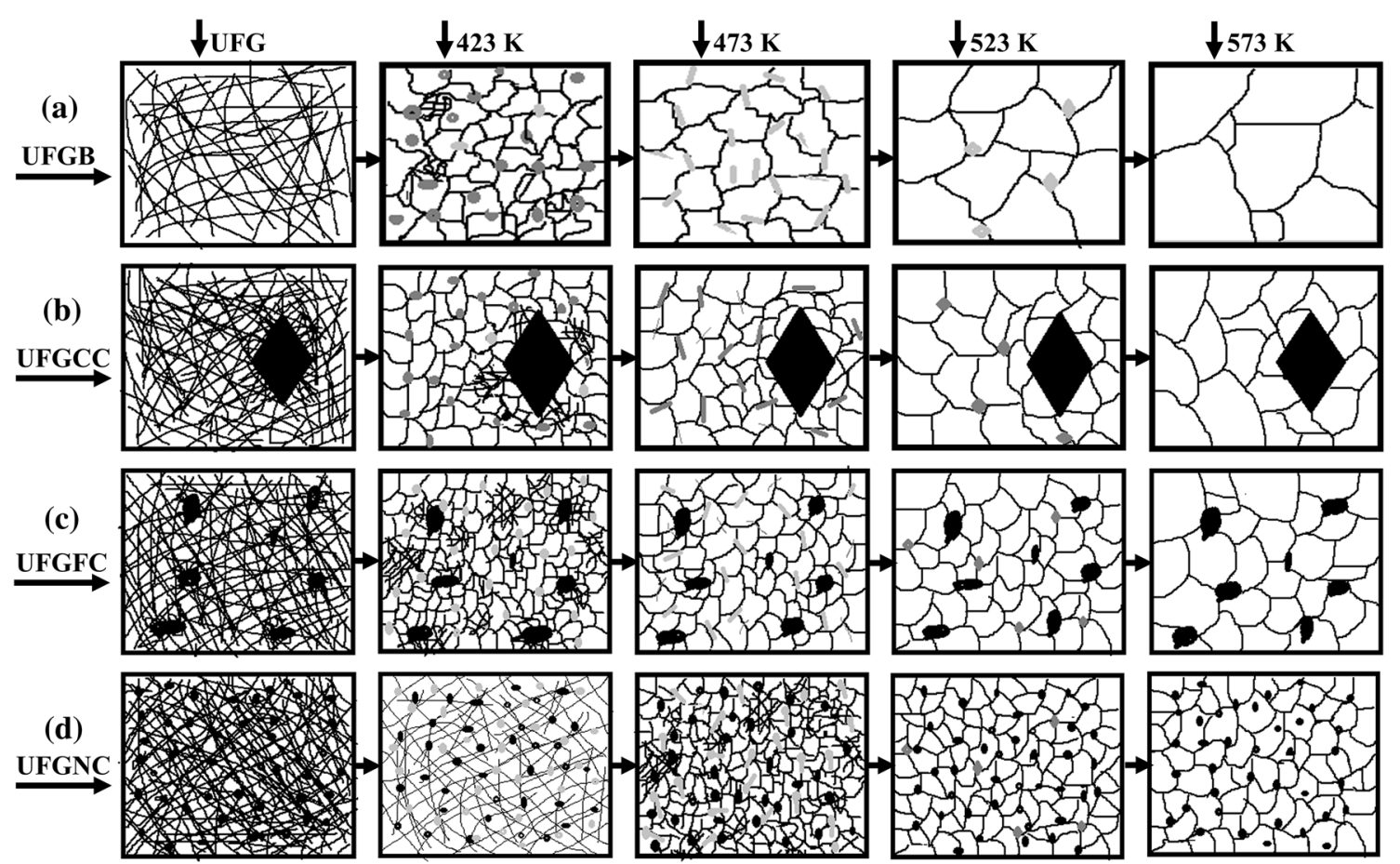

Fig. 14 -Schematic representation of the effects of varying reinforcement sizes, precipitation, and PSN on the microstructural evolution of (a) UFGB, $(b)$ UFGCC, $(c)$ UFGFC, and (d) UFGNC at pre- and post-annealing treatments at various temperatures (the gray-colored circles show the GP zones $/ \beta^{\prime \prime}$ precipitates at $423 \mathrm{~K}$; the gray-colored rod shape shows $\beta^{\prime}$ precipitates at $473 \mathrm{~K}$; the cube or plate shape shows stable $\beta$ precipitates at $523 \mathrm{~K}$ and $573 \mathrm{~K}$; and the black-colored irregularly shaped points show the SiC particles in (b), (c), and (d)).

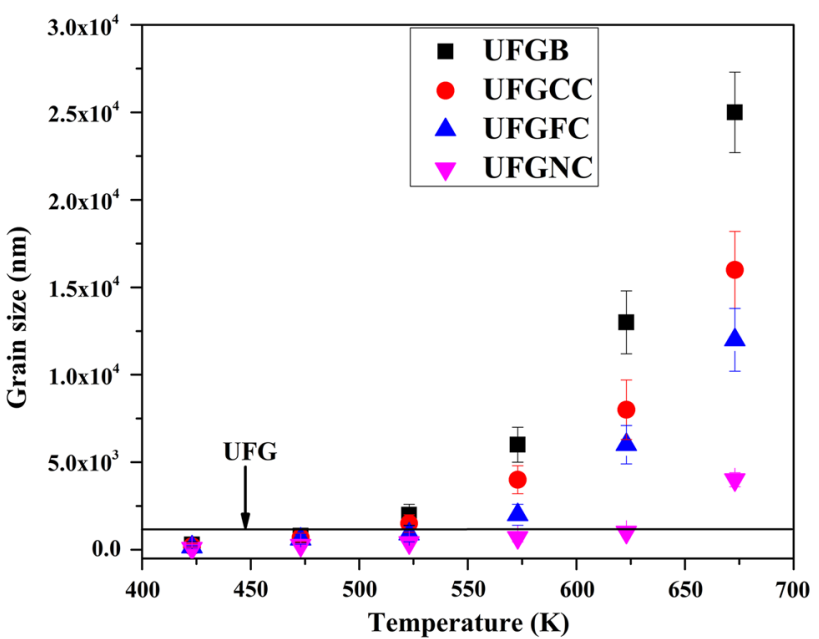

Fig. 15-The grain sizes of UFGB, UFGCC, UFGFC, and UFGNC at various annealing temperatures.

precipitates. These $\beta^{\prime \prime}$ precipitates hindered the dislocation movement and grain boundary migration during tensile straining and thereby enhanced the strength. Even though $\beta^{\prime \prime}$ precipitates and $\mathrm{SiC}$ particles provide the highest hardening effect in retaining strength, softening of the matrix and increased grain boundary area aid in accommodating additional dislocations, leading to improved ductility.

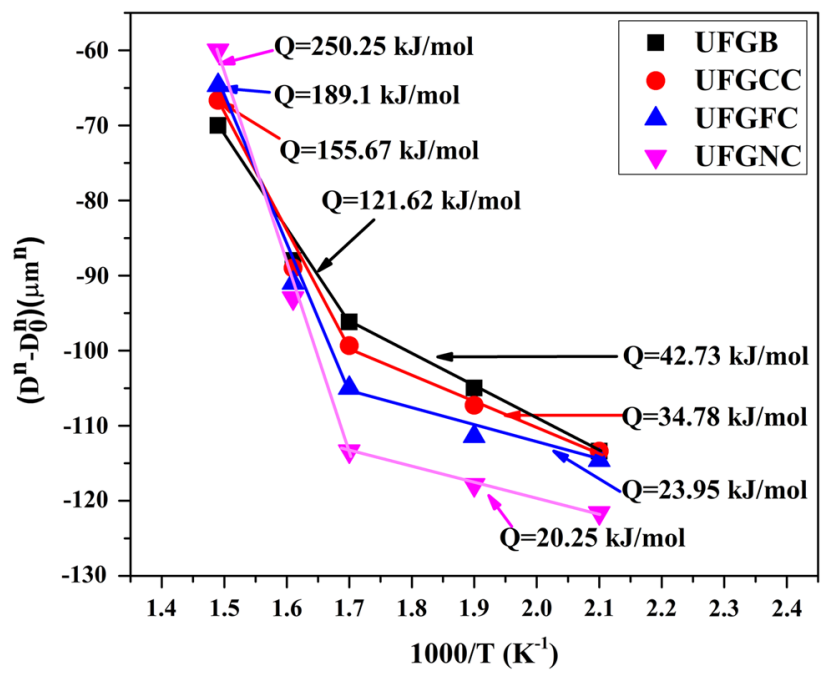

Fig. 16- The effects of varying reinforcement sizes on grain growth kinetics of UFGB, UFGCC, UFGFC, and UFGNC at various annealing temperatures.

Grain coarsening along with a drastic reduction in dislocation density was observed in the UFGB, UFGCC, and UFGFC at annealing temperatures of $523 \mathrm{~K}$ and $573 \mathrm{~K}$. A further decrease in dislocation density and an increase in grain boundary area reduced the strength of the UFG materials by $23.75 \pm 1.8$ pct. In the UFGNC, the grains were in a fine regime $(600 \pm 150$ $\mathrm{nm})$ showing enhanced thermal stability at $573 \mathrm{~K}$ 
annealing. Although the UFGNC was thermally stable up to $573 \mathrm{~K}$, a decrease in strength was observed compared to the nonannealed UFGNC. The coarsening of grains and precipitates at $573 \mathrm{~K}$ reduced the strengthening effect by grain boundary and precipitates in an annealed UFGNC.

At annealing temperatures of $523 \mathrm{~K}$ and $573 \mathrm{~K}$, the recrystallization process was almost completed in the UFGB alloy, showing dislocation-free and coarsegrained microstructure with enhanced ductility. In the UFGCC and UFGFC, a duplex microstructure with ultrafine and fine grain structures was found with reduced dislocation density. The presence of ultrafine grains enhances the strength, whereas fine grains help accommodate more dislocations, and less hindrance to dislocation movement by coarsen precipitates facilitates enhancement in ductility. The UFGCC showed more ductility than the UFGFC and UFGNC. This is because of the reduced dislocation density and increased interparticular distance of $\mathrm{SiC}$ particles in the UFGCC, which provided less obstruction to the dislocation movement and grain boundary migration and thus increased the ductility.

\section{CONCLUSIONS}

The influences of annealing temperatures on the precipitation, microstructural evolution, thermal stability, and grain growth kinetics of UFGB, UFGCC, UFGFC, and UFGNC were examined in detail in the current study. In addition, the influences of varying the reinforcement sizes of $\mathrm{SiC}$ particles on grain growth and thermal stability were studied. The following conclusions are drawn from the present investigation:

1. A severely deformed microstructure was observed in the UFGB, UFGCC, UFGFC, and UFGNC. After annealing, almost all UFG materials showed the beginnings of recovery and recrystallization at 423 K. A fully recrystallized and equiaxed microstructure was observed in almost all UFG materials at $573 \mathrm{~K}$. However, the UFG microstructure remained at $573 \mathrm{~K}$ in the UFGNC due to the effective pinning action of precipitates and nano-SiC particles at the grain boundaries.

2. The precipitation kinetics during annealing are almost the same in the UFGB, UFGCC, UFGFC, and UFGNC materials. The precipitates started evolving with the formation of GP zones at approximately $423 \mathrm{~K}$, followed by the development of metastable $\beta^{\prime \prime}$ and $\beta^{\prime}$ precipitates at $473 \mathrm{~K}$. These precipitates were found to be lying both at the grain interior and along grain boundaries of all UFG materials. The $\beta^{\prime \prime}$ and $\beta^{\prime}$ precipitates were dissolved completely at $523 \mathrm{~K}$, and the formation of stable precipitate $\beta$ occurred. These stable precipitates started coarsening upon further annealing to $573 \mathrm{~K}$. This evolution of precipitates significantly affected the grain growth kinetics.

3. Variation in the reinforcement size of $\mathrm{SiC}$ particles influenced the grain growth kinetics by particle-stimulated nucleation (PSN) and by pinning the grain boundaries in the UFGCC, UFGFC, and UFGNC materials. PSN-based recrystallization was observed in the UFGCC and UFGFC composites, whereas no evidence for the formation of PSN-based recrystallization was observed in the UFGNC. This indicates that the minimum particle size for PSN-based recrystallization is $\geq 1 \mu \mathrm{m}$.

4. Nano $\mathrm{SiC}$ particles and precipitates lowered the grain growth activation energy of UFGNC (20.25 $\mathrm{kJ} / \mathrm{mol}$ ) at low temperature. This was attributed to the high internal stored energy in the UFGNC compared to other UFG materials. At higher temperatures, the grain growth activation energy of the UFGNC $(250 \mathrm{~kJ} / \mathrm{mol})$ was higher than that of other UFG materials (UFGFC $=189.1 \mathrm{~kJ} / \mathrm{mol}$, $\mathrm{UFGCC}=155.67 \mathrm{~kJ} / \mathrm{mol}$ and UFGB $=121.62$ $\mathrm{kJ} / \mathrm{mol}$ ). This is because of the synergetic effect of pinning force exerted by nano-SiC particles and precipitate along the grain boundaries in the UFGNC. This effect retained the microstructure of the UFGNC in the ultrafine grain regime up to an annealing temperature of $573 \mathrm{~K}$, which indicates its excellent thermal stability.

5. Higher strength with moderate ductility was observed in the UFGNC composite than in all other UFG composites and the UFGB in the full annealing temperature zone. This was attributed to the presence of precipitates and the increased number of nano-SiC particles, which hindered the mobility of dislocations and grain boundary migration by pinning action.

\section{ACKNOWLEDGMENTS}

The authors acknowledge the support by DST, India, for the use of the characterization facilities developed under DST-FIST Grant No. SR/FST/ ETII-059/2013(G) Dt: 25-09-2014.

\section{REFERENCES}

1. R. Casati, F. Bonollo, D. Dellasega, A. Fabrizi, G. Timelli, A. Tuissi, and M. Vedani: J. Alloys Compd., 2015, vol. 615, pp. S386-8.

2. M.R. Kamali Ardakani, S. Khorsand, S. Amirkhanlou, and M. Javad Nayyeri: Mater. Sci. Eng. A, 2014, vol. 592, pp. 121-27.

3. R. Taherzadeh Mousavian, R. Azari Khosroshahi, S. Yazdani, D. Brabazon, and A.F. Boostani: Mater. Des., 2016, vol. 89, pp. $58-70$.

4. H. Jafarian, J. Habibi-Livar, and S.H. Razavi: Compos. Part B Eng., 2015, vol. 77, pp. 84-92.

5. A. Ahmadi, M.R. Toroghinejad, and A. Najafizadeh: Mater. Des., 2014, vol. 53, pp. 13-19.

6. A. Hassani and M. Zabihi: Mater. Des., 2012, vol. 39, pp. 140-50.

7. H. Asgharzadeh, S.H. Joo, and H.S. Kim: Metall. Mater. Trans. A, 2015, vol. 46A, pp. 1838-42.

8. F. Khan and S.K. Panigrahi: Mater. Sci. Eng. A, 2016, vol. 675, pp. 338-44.

9. F. Khodabakhshi, A.P. Gerlich, A. Simchi, and A.H. Kokabi: Mater. Sci. Eng. A, 2014, vol. 620, pp. 471-82. 
10. R.J. Immanuel and S.K. Panigrahi: Metall. Mater. Trans. A, 2017, vol. 48A, pp. 3852-68.

11. A. Dhal, S.K. Panigrahi, and M.S. Shunmugam: J. Alloys Compd., 2017, vol. 726, pp. 1205-19.

12. F. Khan and S.K. Panigrahi: J. Alloys Compd., 2018, vol. 747, pp. $71-82$.

13. A. Dhal, S.K. Panigrahi, and M.S. Shunmugam: J. Alloys Compd., 2015, vol. 649, pp. 229-38.

14. N. Kumar and R.S. Mishra: Mater. Charact., 2012, vol. 74, pp. $1-10$.

15. N. Gao, M.J. Starink, and T.G. Langdon: Mater. Sci. Technol., 2009, vol. 25, pp. 687-98.

16. O.B. Bembalge and S.K. Panigrahi: J. Alloys Compd., 2018, vol. 766, pp. 355-72.

17. R.J. Immanuel and S.K. Panigrahi: Mater. Sci. Eng. A, 2018, vol. 712 , pp. $747-56$.

18. F.J. Humphreys and M. Hatherly: Recrystallization and Related Annealing Phenomena, Elsevier Ltd, Oxford, 2004.

19. M. Balog, T. Hu, P. Krizik, M.V. Riglos, B.D. Saller, H. Yang, J.M. Schoenung, and E.J. Lavernia: Mater. Sci. Eng. A, 2015, vol. 648 , pp. $61-71$.

20. S.C. Okumus, S. Aslan, R. Karslioglu, D. Gultekin, and H. Akbulut: Mater. Sci., 2012, vol. 18, pp. 341-46.

21. J. Lipecka, M. Andrzejczuk, M. Lewandowska, J. Janczak-Rusch, and K.J. Kurzydłowski: Compos. Sci. Technol., 2011, vol. 71, pp. 1881-85.

22. V.H. López, A. Scoles, and A.R. Kennedy: Mater. Sci. Eng. A, 2003, vol. 356, pp. 316-25.

23. Z.Q. Yang, L.L. He, J. Chen, H.T. Cong, and H.Q. Ye: J. Mater. Res., 2003, vol. 18, pp. 272-78.

24. Y.L. Wang, R. Lapovok, J.T. Wang, Y.S. Qi, and Y. Estrin: Mater. Sci. Eng. A, 2015, vol. 628, pp. 21-29.

25. Y. Radi and R. Mahmudi: Mater. Sci. Eng. A, 2010, vol. 527, pp. 2764-71.

26. X. Sauvage, G. Wilde, S.V. Divinski, Z. Horita, and R.Z. Valiev: Mater. Sci. Eng. A, 2012, vol. 540, pp. 1-12.

27. Z. Yang, J. Chen, L. He, H. Cong, and H. Ye: Acta Mater., 2009, vol. 57, pp. 3633-44.

28. H.R. Jafarian and J. Habibi-Livar: Bull. Mater. Sci., 2017, vol. 40, pp. $583-90$.

29. M.S. Ghazani and B. Mosadeg: J. Adv. Mater., 2014, vol. 2, pp. $47-54$.
30. S. Cui, R. Mishra, and I.H. Jung: J. Min. Metall. Sect. B, 2018, vol. 54, pp. 119-31.

31. B. Gopi, N. Naga Krishna, K. Sivaprasad, and K. Venkateswarlu: Adv. Mater. Res., 2012, vol. 584, pp. 556-60.

32. G. Williamson and W. Hall: Acta Metall., 1953, vol. 1, pp. 22-31.

33. T. Degen, M. Sadki, E. Bron, U. Konig, and G.N. Nert: Powder Diffr., 2014, vol. 29, pp. S13-18.

34. S.K. Panigrahi and R. Jayaganthan: J. Mater. Sci., 2010, vol. 45, pp. 5624-36.

35. C. Wang, C. Wang, J. Xu, P. Zhang, D. Shan, and B. Guo: Sci. Rep., 2016, vol. 6, pp. 1-10.

36. K.M. Shorowordi, T. Laoui, A.S.M.A. Haseeb, J.P. Celis, and L. Froyen: J. Mater. Process. Technol., 2003, vol. 142, pp. 738-43.

37. Z.P. Luo: Acta Mater., 2006, vol. 54, pp. 47-58.

38. R.M. Wang, M.K. Surappa, C.H. Tao, C.Z. Li, and M.G. Yan: Mater. Sci. Eng. A, 1998, vol. 254, pp. 219-26.

39. D.J. Lloyd, H. Lagace, A. McLeod, and P.L. Morris: Mater. Sci. Eng. A, 1989, vol. 107, pp. 73-80.

40. M. Alizadeh and M.H. Paydar: J. Alloys Compd., 2010, vol. 492, pp. 231-35.

41. J.C. Lee, J.Y. Byun, S.B. Park, and H.I. Lee: Acta Mater., 1998, vol. 46, pp. 1771-80.

42. S. Deb, S.K. Panigrahi, and M. Weiss: Mater. Sci. Eng. A, 2018, vol. 738 , pp. 323-34.

43. S. Valdez, B. Campillo, R. Pérez, L. Martínez, and H. García: Mater. Lett., 2008, vol. 62, pp. 2623-5.

44. L.M. Tham, M. Gupta, and L. Cheng: Acta Mater., 2001, vol. 49, pp. 3243-53.

45. S.K. Panigrahi and R. Jayaganthan: Metall. Mater. Trans. A, 2010, vol. 41A, pp. 2675-90.

46. I. Gutierrez-Urrutia, M.A. Muñoz-Morris, and D.G. Morris: Mater. Sci. Eng. A, 2005, vol. 394, pp. 399-410.

47. F.J. Humphreys: Scr. Mater., 2000, vol. 43, pp. 591-96.

48. M.A. Thein, L. Lu, and M.O. Lai: Compos. Sci. Technol., 2006, vol. 66 , pp. 531-37.

49. T. Niu, W. Chen, H. Cheng, and L. Wang: Trans. Nonferrous Met. Soc. China, 2017, vol. 27, pp. 2300-9.

Publisher's Note Springer Nature remains neutral with regard to jurisdictional claims in published maps and institutional affiliations. 